\title{
Nano-formulation for topical treatment of precancerous lesions: skin penetration, in vitro, and in vivo toxicological evaluation
}

\author{
Maria Natalia Calienni ${ }^{1,2}$. Carlos Facundo Temprana ${ }^{3}$. Maria Jimena Prieto ${ }^{1} \cdot$ Donatella Paolino $^{2} \cdot$ Massimo Fresta $^{4}$. \\ Ayse Begum Tekinay ${ }^{5} \cdot$ Silvia del Valle Alonso ${ }^{1} \cdot$ Jorge Montanari $^{1,5}$ (D)
}

Published online: 30 December 2017

(C) Controlled Release Society 2017

\begin{abstract}
With the aim of improving the topical delivery of the antineoplastic drug 5-fluorouracil (5FU), it was loaded into ultradeformable liposomes composed of soy phosphatidylcholine and sodium cholate (UDL-5FU). The liposome populations had a mean size of $70 \mathrm{~nm}$ without significant changes in 56 days, and the ultradeformable formulations were up to 324-fold more elastic than conventional liposomes. The interaction between $5 \mathrm{FU}$ and the liposomal membrane was studied by three methods, and also release profile was obtained. UDL-5FU did penetrate the stratum corneum of human skin. At in vitro experiments, the formulation was more toxic on a human melanoma-derived than on a human keratinocyte-derived cell line. Cells captured liposomes by metabolically active processes. In vivo toxicity experiments were carried out in zebrafish (Danio rerio) larvae by studying the swimming activity, morphological changes, and alterations in the heart rate after incubation. UDL-5FU was more toxic than free 5FU. Therefore, this nano-formulation could be useful for topical application in deep skin precancerous lesions with advantages over current treatments. This is the first work that assessed the induction of apoptosis, skin penetration in a Saarbrücken penetration model, and the toxicological effects in vivo of an ultradeformable 5FU-loaded formulation.
\end{abstract}

Keywords Ultradeformable liposomes $\cdot 5$-Fluorouracil $\cdot$ Topical delivery $\cdot$ Skin therapy $\cdot$ Zebrafish

\section{Introduction}

Skin cancer, melanoma and non-melanoma, is the most common type of malignancy in the Caucasian population [1].

Jorge Montanari

jmontanari@unq.edu.ar

1 Laboratorio de Biomembranas, Departamento de Ciencia y Tecnología, GBEyB. IMBICE, CCT-LA PLATA, CONICET, Universidad Nacional de Quilmes, Bernal, B1876BXD Buenos Aires, Argentina

2 Department of Experimental and Clinical Medicine, University "Magna Græcia" of Catanzaro, Campus Universitario "S. Venuta", Viale S. Venuta, Germaneto, I-88100 Catanzaro, Italy

3 Laboratorio de Inmunología y Virología (LIV), Departamento de Ciencia y Tecnología, CONICET, Universidad Nacional de Quilmes, B1876BXD Bernal, Argentina

4 Department of Health Sciences, University "Magna Græcia” of Catanzaro, Campus Universitario "S. Venuta", Viale S. Venuta, Germaneto, I-88100 Catanzaro, Italy

5 Institute of Materials Science and Nanotechnology, National Nanotechnology Research Center (UNAM), Bilkent University, 06800 Ankara, Turkey
Conventional treatment includes surgery and chemotherapy, but many of the chemotherapeutic agents used present undesirable effects [2]. Nano-technology provides alternatives to traditional therapies and complementary treatments. The encapsulation of antineoplastic agents into nano-drug delivery systems could result in advantages such as high stability, reduction of the total dose required, minimizing the toxic side effects, and reducing the treatment cost significantly $[2,3]$. Transdermal drug delivery offers many advantages over other traditional routes of administration. Transdermal systems are non-invasive, can be self-administered, and enable to bypass the premature metabolism of the drugs in the liver [4].

The stratum corneum (SC) of the human skin is considered as the limiting barrier in transdermal permeation of most molecules [5]. It consists of 10-25 layers of dead, elongated, fully keratinized corneocytes, which are embedded in a matrix of non-phospholipid lipid bilayers, with approximately 10 $20-\mu \mathrm{m}$ thickness and is considered as metabolically inactive $[6,7]$. The $\mathrm{SC}$ is the outermost layer of the epidermis and is the final product of epidermal differentiation [8].

Ultradeformable liposomes (UDL) are highly elastic liposomes capable to penetrate the $\mathrm{SC}$ because they are able to pass through pores much smaller than their own size [8]. This 
property is due to the presence of an edge activator that increases the deformability of the bilayer by affecting the interfacial tension of these vesicles [9]. Therefore, UDL are able to penetrate the skin driven by the transdermal osmotic gradient [10], transporting the encapsulated actives through the epidermal lipid layers [11-13].

5-Fluorouracil (5FU), a hydrophilic anticancer drug used in the treatment of various forms of skin cancer, showed a suitable antitumor effect in the topical treatment of lesions related to squamous cell carcinoma such as actinic keratosis, Bowen's disease, and keratoacanthoma [14]. Moreover, since the ' $70 \mathrm{~s}$, diverse articles reported the effectiveness of $5 \mathrm{FU}$ in the treatment of basal cell carcinoma but only when it was superficial $[15,16]$. $5 \mathrm{FU}$ per se shows a poor percutaneous permeation thus reducing its anticancer effectiveness following topical administration in deep lesions. Therefore, an increased percutaneous permeation of 5FU could improve the effectiveness of the topical therapeutic approach.

Zebrafish (Danio rerio) develop most of the main organ systems present in mammals during the first week of life; some organs and tissues have been shown to be similar to those of mammals at anatomic, physiological, and molecular levels [17]. As zebrafish larvae develop in a short period of time, ex utero, and are transparent, they are ideal for nano-particle and drug analysis with noninvasive techniques [18].

In this work, a UDL formulation of 5FU for topical therapy of deep skin precancerous and cancerous lesions was obtained and characterized. The skin penetration profile was studied with the Saarbrücken penetration model (SPM). The antitumor activity and cytotoxicity were assessed in two cell lines of human origin by three complementary biochemical assays. In addition, uptake of the nano-formulation and induced cell death mechanisms (in terms of apoptosis and necrosis) were studied. Finally, developmental toxicity assays were carried out on zebrafish model in vivo.

\section{Materials and methods}

\section{Materials}

Soybean phosphatidylcholine (SPC) was purchased from Avanti ${ }^{\circledR}$ Polar Lipids. 5FU was an injectable solution from Laboratorios Filaxis (Buenos Aires, Argentina); sodium cholate (NaChol), 1,2-dimyristoyl-sn-glycero-3phosphoethanolamine-N-(Lissamine ${ }^{\mathrm{TM}}$ rhodamine $\mathrm{B}$ sulfonyl), fluorescein isothiocyanate, merocyanine 540, and sephadex G-50 were purchased from Sigma-Aldrich (Buenos Aires, Argentina). Sodium carboxymethylcellulose was from Fluka-BioChemika (Sigma-Aldrich, Argentina). 6-
Dodecanoyl-2-dimethylaminonaphthalene was purchased from Thermo Fisher Scientific (Buenos Aires, Argentina). Crystal violet, neutral red (NR), ethanol, and methanol were from BioPack (Buenos Aires, Argentina). Chloroform was from J.T.Baker®. 3-[4,5-Dimethylthiazol-2-yl]-3,5-diphenyltetrazolium bromide salt was obtained from Life Technologies $^{\mathrm{TM}}$ (Thermo Fisher Scientific Inc., Argentina). Minimum essential medium, RPMI 1640 medium, fetal bovine serum, glutamine, pyruvate, penicillin, and streptomycin were obtained from Gibco (Waltham, MA, USA). Brine shrimp (Artemia persimilis) was from Biosima SRL (Buenos Aires, Argentina). All other reagents used were from analytical grade.

\section{Ultradeformable liposome preparation}

UDL were prepared by mixing SPC and NaChol, as border activator $(6: 1 w / w$ ratio). The mixture was solubilized in $\mathrm{CHCl}_{3}: \mathrm{CH}_{3} \mathrm{OH}(1: 1 \mathrm{v} / \mathrm{v})$. It was rotary evaporated at $40{ }^{\circ} \mathrm{C}$ in round bottom flask until organic solvent elimination. The thin lipid film was flushed with $\mathrm{N}_{2}$ and rehydrated with $10-\mathrm{mM}$ Tris- $\mathrm{HCl}$ buffer plus $\mathrm{NaCl}$ $0.9 \% \mathrm{w} / \mathrm{v}, \mathrm{pH} 7.4$ (Tris buffer), up to a final concentration of $40 \mathrm{mg} \mathrm{SPC} / \mathrm{ml}$. The resultant liposomal suspension was reduced in size and lamellarity by three sonication cycles of $30 \mathrm{~s}$ with a tip displacement of $10 \mu \mathrm{m}$ and $17.5 \mathrm{~W}$ of power (titanium probe-type ultrasonic homogenizer, Malvern Mastersizer), separated by periods of $30 \mathrm{~s}$ at room temperature. Conventional liposomes (CL), non-ultradeformable, were prepared by the same procedure than UDL but without NaChol.

An ethanolic extract from blueberry (Vaccinium myrtillus, "Millenia" variety) rich in antioxidants was obtained as described by Montanari et al. [19]. The blueberries were harvested in December 2015 at latitude $33^{\circ} 45^{\prime} \mathrm{S}$, longitude $59^{\circ} 45^{\prime} \mathrm{W}$, and elevation $36 \mathrm{~m}$. The blueberry extract was solubilized in Tris buffer in a concentration of $6.13 \mathrm{mg} / \mathrm{ml}$ (BE).

Basically, the same steps mentioned above were followed to incorporate in the aqueous phase, during the film hydration, 5FU $0.25 \% w / v$ (UDL-5FU and CL-5FU) and 5FU plus BE (UDL-5FU-BE). Double-labeled fluorescent UDL-5FU (FUDL-5FU) and CL-5FU (FCL-5FU) were prepared by adding fluorescein isothiocyanate (FITC) $1 \mathrm{mM}$ to the hydration buffer and co-solubilizing with lipids in the organic solution 1,2-dimyristoyl-sn-glycero-3phosphoethanolamine-N-(Lissamine ${ }^{\mathrm{TM}}$ rhodamine B sulfonyl) (Rh-DPPE), in a molar ratio Rh-DPPE:SPC of 1:1000. In all cases, non-incorporated 5FU, BE, and FITC were separated by gel permeation chromatography in a Shepadex G-50 column using minicolumn centrifugation method adapted from Fry et al. [20]. 


\section{Entrapment efficiency and drug lipid ratio}

Concentration of encapsulated 5FU was determined by spectrophotometry at $266 \mathrm{~nm}$ (Jasco V-550, Tokyo, Japan) after complete disruption of one volume of liposomal suspension in two volumes of ethanol. The entrapment efficiency (EE\%) was determined as the percentage of the mass incorporated within the UDL (ED) and the initial mass of drug added (TD), according to the following equation:

$E E \%=\frac{E D}{T D} * 100$.

Liposomal phospholipids were quantified by a colorimetric determination method with ammonium ferrothiocyanate as described by Stewart [21]. The drug:phospholipid ratio of UDL-5FU was determined.

\section{Determination of size, surface charge, and stability}

To assess mean vesicle size and superficial charge, dynamic light scattering (DLS) and zeta potential were performed with a particle size analyzer 90 Plus (Brookhaven Instruments Corporation). These parameters were measured just after preparation and followed through time to determine stability. Negative staining transmission electron microscopy images of liposomes upon uranyl acetate staining were obtained (Zeiss EM 109T transmission microscope, Germany).

The stability of UDL and UDL-5FU was also assessed using Turbiscan Lab® Expert (Formulaction, L'Union, France). The variation of their backscattering $(\Delta B S)$ and transmission $(\Delta T)$ profiles as a function of time was analyzed. Briefly, the samples were diluted $1 / 10$ in Tris buffer and were placed in a cylindrical glass cell, which was scanned from bottom to top. The measurements were performed for $1 \mathrm{~h}$ at $4^{\circ}$ (storage temperature), $25^{\circ}$ (room temperature), and $37^{\circ} \mathrm{C}$ (body temperature). For the comprehensive evaluation of global stability, the Turbiscan Stability Index (TSI) was calculated with Turbiscan Easy Soft, according to Eq. (2).

$\mathrm{TSI}=\sum_{\mathrm{i}} \frac{\sum|S C A N \mathrm{i}(\mathrm{h})-S C A N \mathrm{i}-1(\mathrm{~h})|}{H}$

where $S C A N_{\mathrm{i}}(\mathrm{h})$ is the average backscattering for each time ( $i$ ) of measurement, $S C A N_{\mathrm{i}-1}(\mathrm{~h})$ is the average backscattering for the $i-1$ time of measurement, and $H$ is the sample height. The TSI takes into account all single scan during the experiment and its value is obtained from their average. Lower values of TSI correspond to a more stable system [22].

\section{Drug-membrane interaction}

The interaction of 5FU with the liposomal membrane was assessed by three complementary methods: differential scanning calorimetry (DSC), merocyanine 540 (MC540), and 6dodecanoyl-2-dimethylaminonaphthalene (Lauran) probes.

Temperature of phase transition $\left(T_{\mathrm{m}}\right)$ and associated change of enthalpy $\left(\Delta H_{\text {cal }}\right)$ of UDL and UDL-5FU were determined by DSC from -50 to $30{ }^{\circ} \mathrm{C}$ at $10{ }^{\circ} \mathrm{C} / \mathrm{min}$ rate with an isotherm at $50{ }^{\circ} \mathrm{C}$ of $10 \mathrm{~min}$, in a DSC Q200 (TA-Instruments). Samples $(10 \mathrm{mg})$ were weighed in TA hermetic alodined pans and tightly sealed with a TA hermetic alodined lid. Thermodynamic parameters were calculated with TA Universal Analysis software.

MC540 is a lipophilic dye that can be used quantitatively to study phospholipid packing of lipid vesicles [23]. In water, the MC540 shows two spectrum maximum (the dimer form at $500 \mathrm{~nm}$ and the monomer form at $530 \mathrm{~nm}$ ), whereas in hydrophobic environments the maximum are shifted toward 530 (dimer) and $570 \mathrm{~nm}$ (monomer) [24]. The hydrophobicity factor (HF) is the ratio of the absorbance at $570 \mathrm{~nm}$ respect to $500 \mathrm{~nm}$. Liposome formulations were diluted with Tris buffer until a concentration of $172.04 \mu \mathrm{M}$ of SPC. MC540 was added in aliquots to give a final concentration of $0.768 \mu \mathrm{M}$ until a probe:lipid ratio 1:200 mol:mol. The sample was allowed to equilibrate for $2 \mathrm{~min}$ and then a scan between 400 and $600 \mathrm{~nm}$ was obtained with a UV-Vis spectrophotometer. Measurements were performed at room temperature and baseline correction was done to avoid scattering with liposomes without MC540 [25]. HF was calculated as:

$\mathrm{HF}=\frac{A 570}{A 500}$

The analysis with Laurdan probe was based on the fluorescence spectral shift of Laurdan which can be attributed to dipolar relaxation phenomena, originating from the sensitivity of the probe to the polarity of its environment [26]. Laurdan concentration was $0.33 \mathrm{~mol} \%$ with respect to the total lipids [27]. The probe was added to the lipids with the organic solvent prior to evaporation and the samples were measured by fluorescence spectroscopy (FluoroMate FS2, SCINCO, Korea). When lipids are in the gel phase, Laurdan maximum is located at $440 \mathrm{~nm}$; and when lipids are in the liquid crystalline phase, the maximum emission of this probe is at $490 \mathrm{~mm}$ [28]. Emission intensity was then acquired at 443 (I443) and $485 \mathrm{~nm}$ (I485) (excitation wavelength of $340 \mathrm{~nm}$ ) at room temperature [27]. Generalized polarization (GP) was calculated from the emission intensities using the following equation adapted from the work of Hollmann et al. 2010:

$\mathrm{GP}=\frac{I 443-I 485}{I 443+I 485}$ 


\section{Deformability test}

The deformability of UDL, UDL-5FU, and CL-5FU (with similar size) was determined driving $2 \mathrm{ml}$ of each formulation by an external pressure of $1 \mathrm{MPa}$ of $\mathrm{N}_{2}$, through one $50-\mathrm{nm}$ pore size polycarbonate membrane, in a Lipex 10-ml Thermobarrel Extruder (Transferra Nanosciences, Vancouver, Canada) [29]. Extruded volume was collected every minute along $15 \mathrm{~min}$ and percentage of phospholipid was determined for each fraction.

\section{Drug release}

Drug release was evaluated in duplicate in vitro using centricons (Amicon ${ }^{\circledR}$ Ultra-0.5 Centrifugal Filter Devices, Merck, Darmstadt, Germany) with membrane of cellulose with molecular cutoff of $3 \mathrm{kDa}$. Within a period of $24 \mathrm{~h}$, $3 \mathrm{ml}$ of UDL-5FU, UDL and 5FU were placed into polypropylene tubes, which were constantly stirred $(120 \mathrm{rpm})$ and warmed to $37 \pm 1{ }^{\circ} \mathrm{C}$. At predetermined time intervals $(0$, $0.5,1,2,4,8,12$, and $24 \mathrm{~h}$ ), $200 \mu \mathrm{l}$ of the sample was withdrawn and replaced with an equal volume of fresh Tris buffer. Samples were centrifuged $40 \mathrm{~min}$ in centricons at $14,000 \mathrm{~g}$ at $4{ }^{\circ} \mathrm{C}$. The filtrates (drug release from the liposomes) were analyzed by UV-Visible absorbance (NanoDrop 2000, Thermo Scientific, Waltham, MA, USA). The absence of liposomes in the filtrates was confirmed by phospholipid quantification [21]. The percentage of released drug was calculated according to the following equation:

Drug release $(\%)=\frac{\text { mean cumulative mass in the filtrate }}{\text { initial mass of drug }} * 100$.

\section{In vitro skin penetration studies}

Samples of a healthy adult human skin were obtained from abdominal reduction surgery of a Caucasian woman (39 years old). After excision, the subcutaneous fatty tissue was removed; the SC surface was cleaned with water, wrapped in aluminum foil, and stored in polyethylene bags at $-20{ }^{\circ} \mathrm{C}$ until use [30,31].

Disks of $24 \mathrm{~mm}$ in diameter were punched out from frozen skin, thawed, cleaned with Tris Buffer, and transferred directly into the SPM device [31]. The skin was put onto a filter paper soaked with Tris buffer and placed into the cavity of the Teflon block of the SPM. A volume of $50 \mu \mathrm{l}$ of free 5FU, UDL-5FU, FUDL-5FU, and FCL-5FU were applied under non-occlusive conditions to the skin surface and incubated for $1 \mathrm{~h}$ at $35 \pm$ $1{ }^{\circ} \mathrm{C}$.

\section{Tape stripping}

After the incubation in the SPM device, five skin specimens were segmented using tape stripping method as described by Montanari et al. [12]. The formulation was wiped off from the skin surface using cotton. Then the skin piece was mounted on aluminum using small pins to stretch the tissue and successively stripped with 20 pieces of adhesive tape (Doble $A \circledR$, Abrasivos Argentinos SAIC), covering the whole surface of the skin segments. Each tape was charged with a weight of $2 \mathrm{~kg}$ per $10 \mathrm{~s}$ and rapidly removed. After the tape stripping the remaining skin below the $\mathrm{SC}$, the viable epidermis and the dermis were cut into small pieces and homogenized. The extraction of 5FU from the tapes and VED was done with ethanol:water $(1: 1 v / v)$, stirred for $1 \mathrm{~h}$ at $190 \mathrm{rpm}$ at $37{ }^{\circ} \mathrm{C}$. Tapes were grouped as 1-10 (upper SC), 11-20 (lower SC), and VED (viable epidermis and dermis). The tape stripping was done by quintuplicate, and blanks from tapes and VED from non-incubated samples were subtracted. The presence of $5 \mathrm{FU}$ was determined by UV-Vis spectroscopy at $266 \mathrm{~nm}$. The $5 \mathrm{FU}$ quantified was relativized to the initial concentration of $5 \mathrm{FU}$ in each condition and reported as the percentage of this ratio.

The same procedure was carried out with five skin specimens incubated with FUDL-5FU and FCL-5FU. In this case, each individual tape and VED were extracted with ethanol:water solution, and the penetration profile was measured by fluorescence spectroscopy.

\section{Optical scanning}

After incubation with FUDL-5FU, the full skin thickness was optically scanned at $6-\mu \mathrm{m}$ increments through the $z$-axis by confocal laser scanning microscopy (CLSM) equipped with a laser diode ( exc $488 \mathrm{~nm}$ for FITC excitation) and a $\mathrm{He}-\mathrm{Ne}$ laser ( exc $543 \mathrm{~nm}$ for Rh-DPPE excitation) (Olympus FluoView FV300). Fluorescence intensity of each layer was analyzed by ImageJ software.

\section{Skin cryosectioning}

After incubation with FUDL-5FU, the skin was rapidly frozen, embedded in OCT, and sliced at $-20{ }^{\circ} \mathrm{C}$ in sections of $30-\mu \mathrm{m}$ thickness perpendicular to the skin surface, with a Leica CM 1850 cryostat (Leica Microsystems, Nussloch, Germany). Skin slices were observed by CLSM. The penetrance of both labels into the skin was measured by ImageJ software. The same specimens were also subjected to hematoxylin and eosin staining in order to detect the possible presence of histological alterations. 


\section{Evaluation of antitumor activity}

Cell viability upon 4 and $24 \mathrm{~h}$ of incubation with UDL, ULD5FU, UDL-5FU-BE, and 5FU was determined by three different biochemical assays on immortalized human non-tumorigenic keratinocytes HaCaT and human melanoma cells SK-Mel-28. Both cell lines were obtained from the Instituto Multidisciplinario de Biología Celular (IMBICE-CICCONICET, Argentina). Cells were maintained at $37{ }^{\circ} \mathrm{C}$ with $5 \% \mathrm{CO}_{2}$ in medium supplemented with $10 \%$ heat-inactivated fetal bovine serum (FBS), 2-mM glutamine and 100-UI/ml penicillin, $100-\mu \mathrm{g} / \mathrm{ml}$ streptomycin, and $0.25-\mu \mathrm{g} / \mathrm{ml}$ amphotericin B. HaCaT was maintained in RPMI 1640 and SK-Mel-28 in MEM supplemented with 1-mM sodium pyruvate.

Cells were seeded at a density of $1 \times 10^{4}$ cells/well in 96well flat bottom microplates. After $24 \mathrm{~h}$ of incubation at $37{ }^{\circ} \mathrm{C}$, the medium was replaced with $100 \mu \mathrm{l}$ of UDL, UDL-5FU, UDL-5FU-BE, and 5FU diluted in cell medium. The 5FU concentration assessed ranged from 0.18 to $114.4 \mu \mathrm{M}$ and corresponded to concentrations of SPC from 0.033 to $20.6 \mathrm{mM}$.

After incubation, the media with the treatments were removed. Cell monolayers were washed twice with PBS, and the MTT, crystal violet (CV), or NR assays were performed.

For MTT, fresh medium containing $0.5 \mathrm{mg} / \mathrm{ml}$ of tetrazolium salt [3-(4,5-dimethyl-thiazol-2-il)-2,5-diphenyl tetrazolium] was added and removed after $2 \mathrm{~h}$ of incubation at $37^{\circ} \mathrm{C}$. The formazan crystals formed were dissolved in $200 \mu$ l of DMSO, and absorbance at $570 \mathrm{~nm}$ was measured by using a Rayto RT-2100C microplate reader (Nashan, Shenzhen, China).

For $\mathrm{CV}, 100 \mu \mathrm{l}$ of crystal violet solution was added and cells were incubated $15 \mathrm{~min}$ at $37^{\circ} \mathrm{C}$ in a humidified chamber. $\mathrm{CV}$ was removed and the plate was immersed into distillated water. Then $100 \mu \mathrm{l} /$ well of a $30 \%$ acetic acid solution was added to dissolve the crystals and absorbance was measured at $530 \mathrm{~nm}$ in a microplate reader.

For NR assay, $200 \mu \mathrm{l}$ of $50-\mu \mathrm{g} / \mathrm{ml}$ neutral red solution was added and cells were incubated $3 \mathrm{~h}$ at $37^{\circ} \mathrm{C}$. Then, $200 \mu \mathrm{l}$ of fixation solution of formaldehyde $1 \%$ was added and removed after 2 min washing with saline solution $(\mathrm{NaCl} 0.9 \%) .200$ microliters of revealing solution that consisted in ethanol $50 \%$ and glacial acetic acid $1 \%$ was added to each well, homogenized, and the absorbance was read in a microplate reader at $540 \mathrm{~nm}$.

The percentage of cell viability was calculated according to the following equation:

Cell viability $(\%)=\frac{A b s T}{A b s C} \times 100$

where $\mathrm{Abs} \mathrm{T}$ is the absorbance of treated cells and $\mathrm{Abs} \mathrm{C}$ is the absorbance of control (untreated) cells. The formazan, $\mathrm{CV}$, and NR concentration are directly proportional to the cell viability that was reported as the mean of three different experiments \pm SD.

\section{Evaluation of cell apoptosis}

The evaluation of the apoptotic and necrotic induction was carried out with the Annexin V-FITC apoptosis detection kit (BD Pharmingen ${ }^{\mathrm{TM}}$ ). Cells were seeded at a density of $3 \times 10^{5}$ cells/well in 6-well plates and allowed to grow for $24 \mathrm{~h}$. The medium was then replaced with fresh medium without FBS containing UDL-5FU, UDL-5FU-NB, and $5 \mathrm{FU}(114.4 \mu \mathrm{M}$ of $5 \mathrm{FU}$ ) and cells were incubated at $37^{\circ} \mathrm{C}$ with $5 \% \mathrm{CO}_{2}$. After $6 \mathrm{~h}$ of exposure, the media were removed; cells were washed three times with PBS and trypsinized. Trypsin was inactivated with FBS; cells were centrifuged at $125 \times g$ and cell density adjusted to $1 \times 10^{6}$ cells $/ \mathrm{ml}$ in $1 \times$ binding buffer. The staining was performed according to the manufacturer's instruction. Briefly, $100 \mu \mathrm{l}\left(1 \times 10^{5}\right.$ cells $)$ of the cell suspension was stained with $5 \mu \mathrm{l}$ of Annexin V-FITC and/or $5 \mu \mathrm{l}$ PI, gently vortex, and incubated for $15 \mathrm{~min}$ at room temperature in the dark. Then, $400 \mu \mathrm{l}$ of $1 \times$ binding buffer were added. A total of $1.9 \times 10^{4}$ cells was analyzed within $1 \mathrm{~h}$ by flow cytometry (Becton Dickinson FACSCalibur). Data was processed using CellQuest Pro software.

\section{Liposomal cell uptake}

Cell uptake of the FUDL-5FU was followed upon incubation on $\mathrm{HaCaT}$ and SK-Mel-28 cells by fluorescence microscopy. Liposomal cell uptake was determined on both cell types grown $24 \mathrm{~h}$ on coverslips in 6-well plates. After $3 \mathrm{~h}$ of incubation in the dark at $37{ }^{\circ} \mathrm{C}$ (optimum temperature of growth) and at $4{ }^{\circ} \mathrm{C}$ (temperature at which internalization by endocytic uptake is absent due to reduced metabolism of cells [12]), liposomal suspensions were removed, cells were washed, and coverslips were mounted on a fluorescence microscope (Nikon Alphaphot-2 YS2, Japan). RAW 264.7 cell line was used as a positive control of phagocytosis. The image merge was carried out using ImageJ software (US NIH, Bethesda, Maryland, USA).

\section{In vivo toxicity evaluation}

Studies were carried out on zebrafish larvae between 4 and 7 days post-fecundation (dpf). Wild-type adult zebrafish were maintained in tanks at $26 \pm 1{ }^{\circ} \mathrm{C}$ with a cycle of $14 / 10 \mathrm{~h}$ of light/dark. Adult zebrafish were fed with dry fake food (TetraMin PROß) three times a day and once with live brine shrimp (A. persimilis). Water was constantly aerated and maintained at $\mathrm{pH}$ 7.0-8.0. After spawning and fertilization, the embryos were collected and conserved in $\mathrm{E} 3$ medium $\left(\mathrm{NaCl} 0.29 \mathrm{~g} / \mathrm{l}, \mathrm{KCl} 0.012 \mathrm{~g} / 1, \mathrm{CaCl}_{2} 0.036 \mathrm{~g} / \mathrm{l}, \mathrm{MgSO}_{4}\right.$ 
$0.039 \mathrm{~g} / 1$ in deionized water, and 50-ppb methylene blue to inhibit fungal growth). Only fertilized eggs in good conditions were selected for further treatments. After $1 \mathrm{dpf}$, three zebrafish embryos were placed in each well of a 96 -well microplate containing E3 medium and maintained at $28 \pm 1{ }^{\circ} \mathrm{C}$ until $4 \mathrm{dpf}$ in the same conditions of light than adults.

\section{Zebrafish exposure}

At 4 dpf, the medium was removed and replaced with $250 \mu \mathrm{l}$ of the serial dilutions in E3 medium of 5FU, UDL-5FU, or with $\mathrm{E} 3$ for control. The treatment solution was not removed during the study and larvae were maintained at $28 \pm 1{ }^{\circ} \mathrm{C}$ with a 14/10-h light/dark cycle. The range of $5 \mathrm{FU}$ concentration tested was $1.25-20 \mathrm{mM}$ for free $5 \mathrm{FU}$ and $1.83-117 \mu \mathrm{M}$ (0.825-52.8-mM SPC) for UDL-5FU. Different concentrations of free or encapsulated 5FU were tested in order to study the range of concentrations that produce detectable effects.

Swimming activity, alterations in heart rate, and morphological changes were assessed in the same group of larvae.

\section{Measurement of the swimming activity}

Activity events were recorded for $15 \mathrm{~min}$ at $4,24,48$, and $72 \mathrm{~h}$ post-incubation (hpi) at room temperature with an automated device with a system of infrared detection (WMicrotracker, Designplus SRL, Buenos Aires, Argentina) [32]. Swimming activity was determined as the number of interruptions of the infrared microbeam arrangement for $15 \mathrm{~min}$ and data were relativized to the control [33]. A total of eight wells per condition were analyzed by triplicate.

\section{Measurement of the heart rate and morphological changes}

The heart rate and morphological changes were assessed at 72 hpi as described by Igartúa et al. 2015. Briefly, control and treated zebrafish larvae were individually transferred into a well of a 96-well microplate and immobilized with sodium carboxymethylcellulose. Eight larvae per condition were photographed and a video was recorded with a Microsoft LifeCam Studio camera coupled to a trinocular microscope Nikon SMZ800 (Nikon Corporation, Tokyo, Japan). The heart rate was measured by counting the number of beats over $15 \mathrm{~s}$ and reported as beats per minute (bpm). Larval eye area, rostrocaudal length, spinal cord length, uninflated swim bladder, arched body, tissue ulceration, and pericardial edema were analyzed with ImageJ Software [34, 35].

\section{Statistical analysis}

GraphPad Prism 6.0 was used to conduct all statistical analyses. One-way ANOVA and Dunnett's multiple comparisons post-test were used for statistical analysis. To compare only two conditions, the Student's $t$ test was used. Homoscedasticity was determined with Bartlett's test. For non-normally distributed data or when homoscedasticity was not supported, Kruskal-Wallis test was performed. Only values with $p<0.05$ were accepted as significant.

\section{Results and discussion}

\section{Physicochemical characterization of UDL-5FU}

The preparation method rendered empty UDL of $70 \mathrm{~nm}$ in mean size, with unimodal distribution and negative value of zeta potential. As shown in Table 1, 5FU incorporation did not modify the mean sizes, remaining in the order of $70 \mathrm{~nm}$. Additionally, the liposomal suspensions showed good colloidal stability after storage at $4{ }^{\circ} \mathrm{C}$ for at least 56 days, with no significant changes of size distribution nor polydispersity. Figure 1 depicts electron micrograph of UDL-5FU, which appears as vesicles.

To confirm the results of DLS and zeta potential analysis over time, the stability of UDL and UDL-5FU was studied using the Turbiscan Lab® Expert. This equipment is able to correlate the colloidal and storage stability of the formulations at different temperatures with their backscattering and transmission as a function of time [36]. The principle of this measurement is based on the variation of the droplet volume fraction (migration) or mean size (coalescence), resulting in the variation of backscattering and transmission signals. Thus, it provides information about the kind of destabilization process going on such as creaming or sedimentation (migration events) and coalescence. In addition, with the TSI profile, it is possible to monitor the stability kinetics of the formulations versus aging time. The $\Delta B S$ and $\Delta T$ signals of the formulations were close to the baseline during analysis. A variation of

Table 1 Physicochemical parameters over time of UDL prepared both in presence and absence of $5 \mathrm{FU}$

\begin{tabular}{lllll}
\hline Sample & Days & Mean size $(\mathrm{nm})^{\mathrm{a}}$ & PDI $^{\mathrm{b}}$ & ${\text { Zeta potential }(\mathrm{mV})^{\mathrm{c}}}^{\mathrm{U}}$ \\
\hline UDL & 0 & $70.0 \pm 0.73$ & 0.261 & $-36.97 \pm 5.85$ \\
& 30 & $76.1 \pm 0.99$ & 0.354 & $-35.57 \pm 1.87$ \\
UDL-5FU & 0 & $68.6 \pm 0.80$ & 0.280 & $-25.13 \pm 0.31$ \\
& 30 & $66.8 \pm 1.56$ & 0.318 & $-34.60 \pm 0.57$ \\
& 56 & $83.6 \pm 1.30$ & 0.262 & - \\
\hline
\end{tabular}

${ }^{\text {a }}$ Liposomal suspensions were suitably diluted and analysis was carried out at $20^{\circ} \mathrm{C}$. Mean $\pm \operatorname{SD}(n=3)$

${ }^{\mathrm{b}}$ Polydispersity index

${ }^{\mathrm{c}}$ Liposomal suspensions were suitably diluted and analysis was carried out at $20^{\circ} \mathrm{C}$. Mean $\pm \operatorname{SD}(n=10)$ 


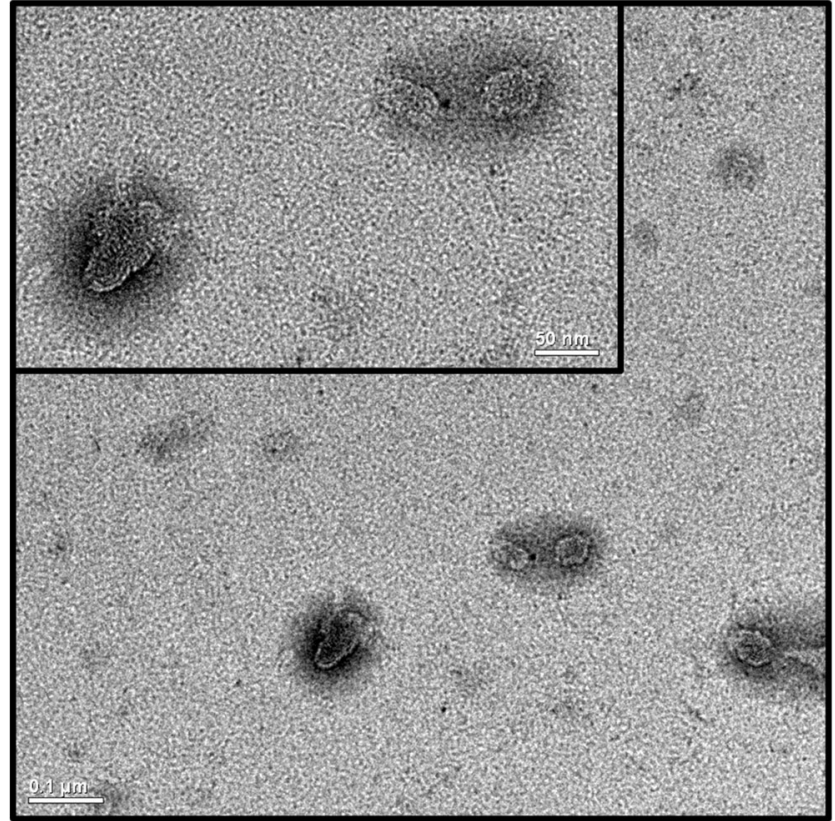

Fig. 1 Transmission electron microscopy of UDL-5FU following negative staining $(\times 100,000)$. Inset $\times 200,000$

the $\triangle B S$ profile within the interval $\pm 5 \%$ evidences a suitable stability of the formulation [37]. Therefore, there was no evidence of instability phenomena on UDL and UDL-5FU at 4, 25 , and $37^{\circ} \mathrm{C}$. The TSI profiles were similar between UDL and UDL-5FU and showed a linear kinetic with a low final TSI value at 25 and $37^{\circ} \mathrm{C} \mathrm{(Fig.} \mathrm{2).} \mathrm{Even} \mathrm{though,} \mathrm{there} \mathrm{was} \mathrm{no}$ significant changes in the $\Delta B S$ and $\Delta T$ profiles at $4{ }^{\circ} \mathrm{C}$, there was a slight discrepancy in the stability kinetic for both formulations and a higher TSI value in comparison to 25 and $37^{\circ} \mathrm{C}$.

Overall results showed that the UDL-5FU was stable over time and the incorporation of 5FU did not alter the own stability of the system. UDL and UDL-5FU were less stable at $4{ }^{\circ} \mathrm{C}$ in comparison to 25 and $37^{\circ} \mathrm{C}$ but could be maintained at least 30 days $4{ }^{\circ} \mathrm{C}$ without significant destabilization phenomena.

Concentration of $5 \mathrm{FU}$ encapsulated was determined as $0.2868 \pm 0.0008 \mathrm{mM}$ (mean $\pm \mathrm{SD}, n=3$ ) after gel permeation chromatography by UV-Vis absorbance by triplicate. Moreover, the drug:lipid ratio after chromatography was $1: 865(\mu \mathrm{g} / \mu \mathrm{g})$.

The entrapment efficiency was $1.4 \%$. UDL-5FU showed EE\% values inversely proportional to the drug initially added for their preparation, highest drug concentrations favored a lower entrapment efficiency (data not shown), as observed by Cosco et al. (2015). This low EE\% was expected according to other efforts to encapsulate 5FU in previous works [38-40]. Kaiser et al. [41] argued that this effect depends on the lipid composition, the packing of the acyl chains, and particularly applies to water-soluble compounds in small liposomes, due to the small ratio between the inner and external volume. Also, Elmeshad et al. [42], observed that there was a directly proportional relationship between the size of the vesicle, the subsequent aqueous space, and the amount of 5FU encapsulated.
Fig. 2 Kinetic stability profiles of UDL (a) and UDL-5FU (b) at 4, 25 , and $37^{\circ} \mathrm{C}$ measured by Turbiscan Lab® Expert
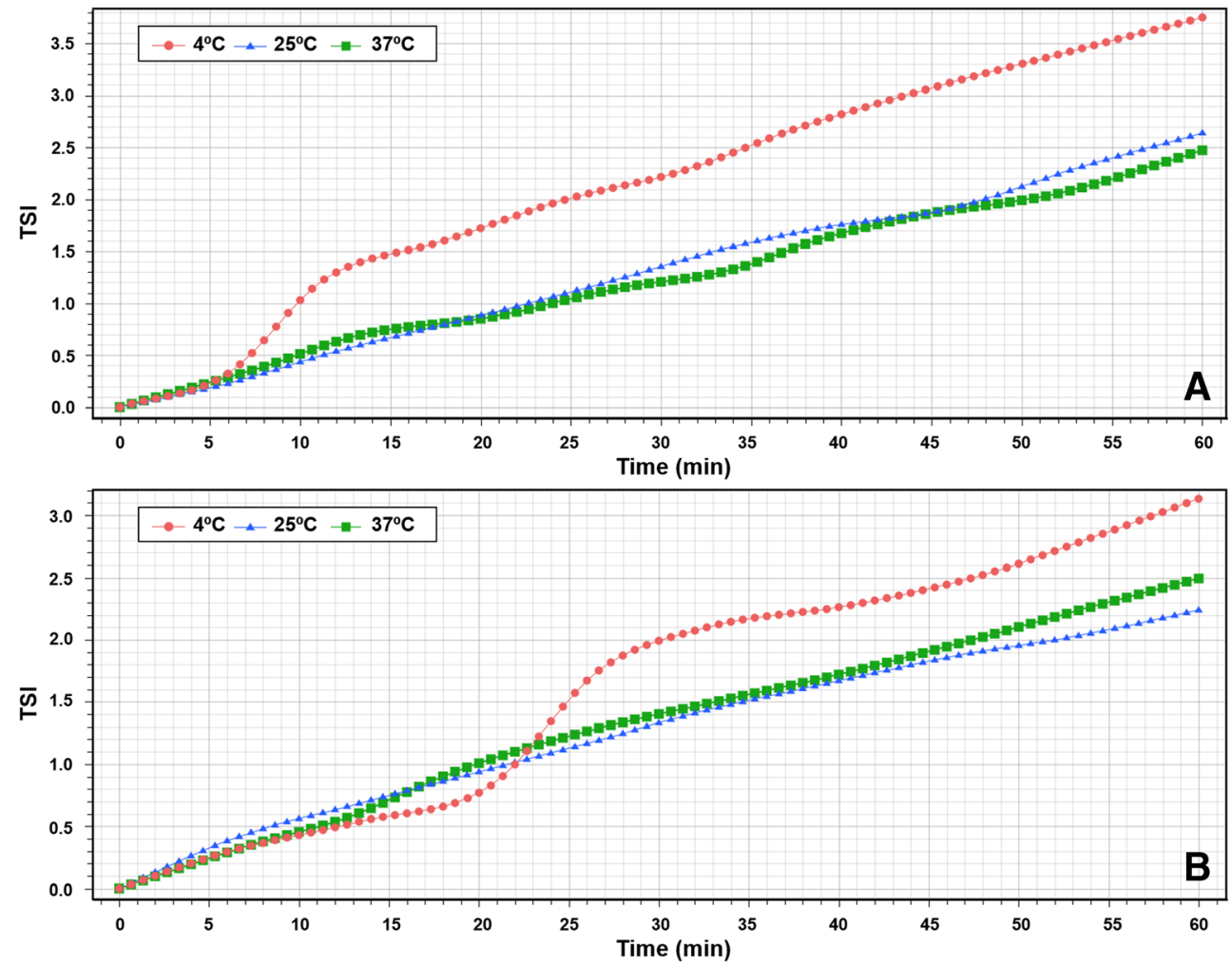
Otherwise, Elorza et al. [43] suggested a tendency of 5FU to remain adsorbed at the outer lipid-water interface. $5 \mathrm{FU}$ could be entrapped within the vesicles and could be adsorbed in the inner and outer membrane surface. Thus, another reason of the low EE\% could be the more or less rapid leakage of $5 \mathrm{FU}$ that there was out of the liposomes weakly retained after removal of the non-entrapped drug. The first evidence to thought in $5 \mathrm{FU}$ adsorption was the significant difference between the zeta potential of the UDL empty and 5FU-loaded. The UDL-5FU reached a similar surface charge than UDL after the passage of time that could be related to the interaction of neutral molecules of 5FU at pH 7.4 (pKa 8-13), with the head groups of phospholipids. As time goes by and 5FU was released, the surface charge decreased (more negative).

\section{Interaction of 5FU with the liposomal membrane}

The determination of the location of 5FU within UDL and its interaction with the lipid bilayer was carried out by DSC and by MC540 and Laurdan probes.

DSC was used to determine the effect of the incorporation of $5 \mathrm{FU}$ in the thermotropic behavior of the liposomal bilayer in aqueous suspension. Thermotropic profiles showed two endothermic peaks, one close to $0{ }^{\circ} \mathrm{C}$ corresponding to fusion of aqueous medium and other, below $0{ }^{\circ} \mathrm{C}$ (Fig. 3). Thermodynamic parameters corresponding to each thermogram are shown in Table 2. The transition temperature obtained showed no significant differences due to incorporation of $5 \mathrm{FU}$ in comparison to empty UDL. However, the incorporation of 5FU into liposomes strongly decreased the phase transition enthalpy and the sharpness of the phase transition temperature peak. These results indicated that $5 \mathrm{FU}$ interacted with the bilayer, therefore produced significant changes in the bilayer organization, decreasing its cooperativity $[44,45]$.

The HF of MC540 probe is a parameter that relates the concentration of monomer in non-polar environment with respect to monomer in an aqueous phase [46]. Thus, the HF

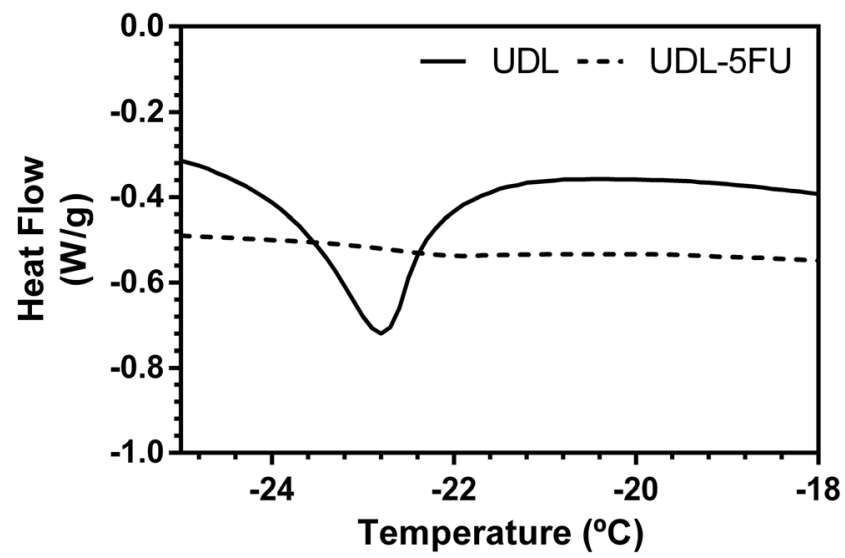

Fig. 3 Differential scanning calorimetry of empty and 5FU-loaded ultradeformable liposomes
Table 2 Effect of incorporation of $5 \mathrm{FU}$ on thermodynamic parameters of the liposomal membrane followed by DSC

\begin{tabular}{lll}
\hline Sample & $T_{\mathrm{m}}{ }^{\mathrm{a}}\left({ }^{\circ} \mathrm{C}\right)$ & $\Delta H_{\mathrm{cal}}{ }^{\mathrm{b}}(\mathrm{J} / \mathrm{g})$ \\
\hline UDL & -22.9 & 3.815 \\
UDL-5FU & -22.2 & 0.258 \\
\hline
\end{tabular}

${ }^{\text {a }}$ Temperature corresponding to the minimum of the calorimetric peak

${ }^{\mathrm{b}}$ Calorimetric enthalpy calculated as the area under the curve

reflects the degree of hydrophobic sites exposed and the organization of liposomal surface. The increase in the HF is related to the exposure of hydrophobic sites in the lipid-water interface, because the MC540 locates as monomer slightly above the domain of the glycerol of backbone of neutral and charged phospholipids [24]. This explains the sensitivity of MC540 to structural variations in the head group region. Significant differences between the HF of UDL and UDL-5FU were observed over time (Table 3). The encapsulation of 5FU resulted in a significantly higher HF value with respect to the empty UDL at 0,7 , and 32 days $(p<0.0001)$. The $5 \mathrm{FU}$ could favor the entry of MC540 to the lipid-water interface because of the interaction with the phosphate head of phospholipids, altering the membrane organization. Although MC540 is an external probe, it would be expected to observe a similar effect at the inner surface of the bilayer.

The excitation and emission fluorescence spectra of Laurdan depend strongly on the phase state of the membrane where it is inserted [47]. Laurdan is located at the hydrophilichydrophobic interface of the bilayer with the lauric acid tail anchored in the phospholipid acyl chain region [26]. Parasassi et al. [48] demonstrated that Laurdan is sensitive to the dynamics as well as to the polarity of the surrounding membrane. Laurdan GP spectra in liposomes allow the determination of the membrane phase state, gel or liquid-crystalline, as well as coexisting phases. The GP value reflects the spectral shift related to differences in the level of hydration between the gel and liquid-crystalline phases [26, 49]. The GP values for the gel and liquid-crystalline phases are 0.6 and -0.2 , respectively, using an excitation wavelength of $340 \mathrm{~nm}$ and emission wavelengths of 440 and $490 \mathrm{~nm}$ [48]. A high GP value indicates less dipolar relaxation, which corresponds to a rigid environment [28]. Because the GP value is independent of the $\mathrm{pH}$ and the type of polar head group, the process of dipolar relaxation which sets the spectral properties is related to the

Table 3 Hydrophobicity factor of empty and 5FU-loaded ultradeformable liposomes over time at $20^{\circ} \mathrm{C}$. Mean $\pm \mathrm{SD}(n=3)$

\begin{tabular}{llll}
\hline Sample & HF 0 days & HF 7 days & HF 32 days \\
\hline UDL & $2.289 \pm 0.014$ & $2.115 \pm 0.075$ & $1.705 \pm 0.041$ \\
UDL-5FU & $2.552 \pm 0.012$ & $2.376 \pm 0.029$ & $2.525 \pm 0.010$ \\
\hline
\end{tabular}


number of water molecules around Laurdan [26]. Therefore, it is the water dipolar relaxation process that produces the spectral shift, as a consequence of the interaction between the probe excited state dipole and the surrounding solvent dipole [26]. Laurdan excitation and emission GP spectra of UDL and UDL-5FU corresponded to liquid-crystalline phase membranes (Fig. 4). However, there was a significant difference between GP value obtained for UDL, $-0.188 \pm 0.003$, and UDL-5FU, $-0.200 \pm 0.002(p<0.01)$. Low values of GP can be attributed to water penetrating the head groups of membrane phospholipids. Therefore, 5FU could contribute to the disorganization of the membrane, altering the packing of phosphate groups but not affecting the phase state. While, the higher GP value of UDL than UDL-5FU, indicated a less dipolar relaxation, which corresponds to a more rigid environment.

By means of the analysis of DSC, MC540, and Laurdan, it was observed that $5 \mathrm{FU}$ interacted with the membrane of the UDL. The molecules of 5FU could be adsorbed at the lipidwater interface with constant access to the aqueous phase. This molecular interaction was assessed previously by Lopes et al. [50] in large unilamellar vesicles of 2-dimyristoyl-snglycero-3-phosphocholine (DMPC), who also observed some degree of penetration into the lipid domain based on nuclear magnetic resonance spectroscopy and steady-state fluorescence anisotropy [50]. Lopes et al. [50] observed timedependent changes in the liposome diffusivity of $5 \mathrm{FU}$, indicating that the drug transport through the membrane was reversible, but the retention within the membrane was poor. Drug-liposome interaction depends on the partition coefficient of the drug, functional groups, size, and polar surface area that is the sum of surfaces of polar atoms in a molecule [51]. 5FU is a partially lipophilic drug with moderate value of partition coefficient, $\log P=-0.824$, and a polar surface area of $65.7 \AA^{2}$ [51]. These two parameters correlate with passive molecular transport through membranes and the possibility

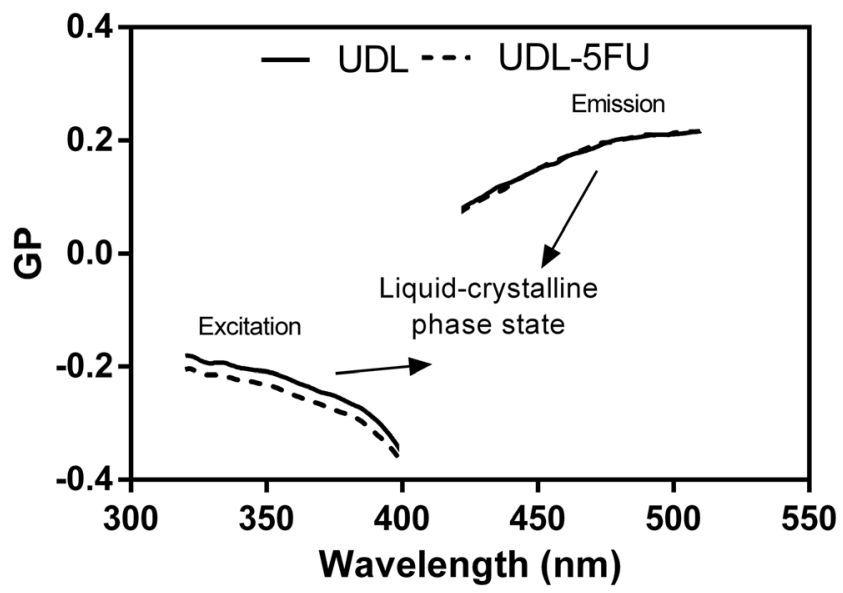

Fig. 4 Laurdan excitation and emission GP spectra of UDL and UDL$5 \mathrm{FU}$ at $20^{\circ} \mathrm{C}$. Average of three independent measurements of superficial adsorption of $5 \mathrm{FU}$ in the inner and outer membrane surface $[50,51]$. Furthermore, at $\mathrm{pH} 7.4,5 \mathrm{FU}$ (pKa 813) is in neutral form and behaves as a surface-active drug with an estimated critical micelle concentration $\mathrm{CMC}=8.0 \times$ $10^{-10} \mathrm{M}$ [52]. Then, the interaction of $5 \mathrm{FU}$ with the waterbilayer interface in UDL-5FU could result in a disorganization and fluidification of the liposomal membrane and could alter the distance between the phospholipids affecting the phase transition enthalpy of the membrane. The results also were consistent with data published about 5FU binding and mobility in bilayer membranes of egg phosphatidylcholine, large unilamellar vesicles of DMPC, and dipalmitoylphosphatidylcholine [50, 51, 53, 54].

\section{Deformability test}

Liposome passage across 50-nm pore size membrane under an external pressure of $1 \mathrm{MPa}$ of $\mathrm{N}_{2}$ is shown in Fig. 5. The profiles of UDL and UDL-5FU showed a biphasic mode, characterized by a fast passage during the first minute followed by a slow passage the rest $15 \mathrm{~min}$. Conversely, no phospholipid passage was registered for CL-5FU during the first 13 min with only $1 \%$ recovered phospholipids at the end of the period time.

As a parameter of deformability, the elasticity of liposome bilayers $(D)$ was calculated according to van den Bergh et al. [55], where $D=J\left(r_{\mathrm{v}} / r_{\mathrm{p}}\right)^{2}$. The flux (J) of liposomes through a nano-porous barrier was calculated as the area under the curve from the plot of liposomal phospholipids passage versus time, $r_{\mathrm{v}}$ is the vesicle size after passage, and $r_{\mathrm{p}}$ is the membrane pore diameter. The results indicated that empty UDL had an elasticity of $D=645.8$, whereas UDL-5FU had an elasticity of $D=486.2$.

ULD resulted 430-fold and UDL-5FU resulted 324-fold more elastic than CL-5FU $(D=1.5)$. Although UDL-5FU had a lower elasticity than UDL, it had a similar behavior when passing through the membrane and the difference is

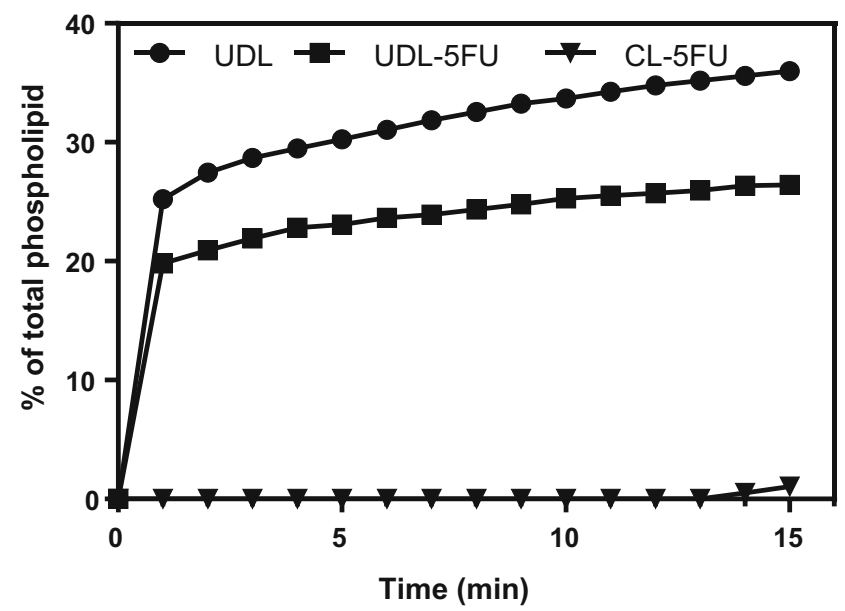

Fig. 5 Profile of phospholipid passage through 50-nm pore size vs. time 
very significant in comparison to the CL-5FU. The reduction of the deformability after the incorporation of $5 \mathrm{FU}$ could be related to the interaction of the $5 \mathrm{FU}$ with the liposomal membrane observed in this work. Nevertheless, UDL-5FU conserved the capacity to cross the skin as observed in the in vitro penetration studies (see below).

\section{Drug release}

The release profile of 5FU from UDL-5FU was studied over time (Fig. 6). During the first $2 \mathrm{~h}$, almost $60 \%$ of the drug was released. This initial burst release could be related to the drug adsorbed in the outer surface of UDL-5FU as observed in the studies with MC540 and Laurdan probes. Around $80 \%$ of the entrapped 5FU was released after $12 \mathrm{~h}$. This behavior was also observed by Cosco et al. [56] in 5FU-loaded UDL with a similar composition. Finally, overall content of UDL-5FU was released during the first $24 \mathrm{~h}$. The $5 \mathrm{FU}$ entrapped in the aqueous core of the liposome was passing through the membrane possibly by passive diffusion because of its moderate partition coefficient, small size, and polar surface area $[50$, 51].

\section{In vitro skin penetration studies}

Skin penetration profile of the hydrosoluble fluorescent dye FITC, co-encapsulated with 5FU in UDL and CL, together with the hydrophobic probe Rh-DPPE, was determined using the SPM followed by segmentation by tape stripping or optical scanning by CLSM up to $60-\mu \mathrm{m}$ depth. Skin penetration also was studied by cryosectioning and CLSM. Finally, the presence of 5FU in the SC and the VED upon incubation as free $5 \mathrm{FU}$ or UDL-5FU was quantified by UV-Vis spectroscopy.

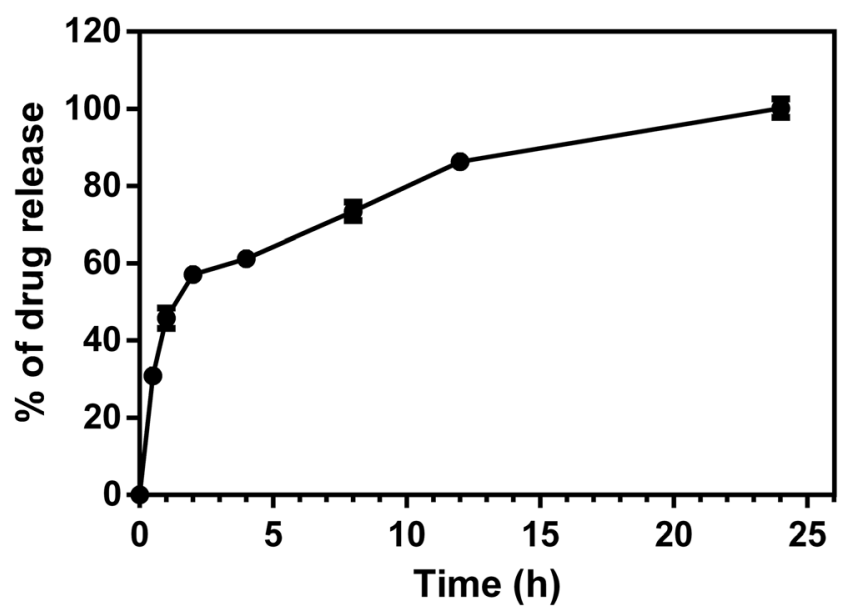

Fig. 6 Release profile of 5FU from UDL-5FU. Experiments were carried out at $37^{\circ} \mathrm{C}$. Mean $\pm \operatorname{SD}(n=2)$
SPM was employed under non-occlusive conditions, in order to maintain the transdermal hydration gradient, that it is proposed to be the locomotive force for UDL penetration $[10,57]$. The SPM, coupled to segmentation techniques such as tape stripping or cryosectioning, allows the measurement of penetration profile of drugs along the skin. The use of SPM ensured that the pass through the skin was exclusively owed to the penetration from top (SC) to lower layers of the epidermis and dermis. The experiments were carried out with the same skin donor, repeated five times, and the distance and geometry of skin stretching during tape stripping were kept constant.

After 1-h incubation in SPM with 5FU solubilized in Tris buffer, followed by removal of material remaining on the skin surface and tape stripping, 5FU was almost not found in quantitative amounts in the tapes and VED (Fig. 7). This result was in concordance with other studies which observed a poor percutaneous permeation of free $5 \mathrm{FU}$, reducing its anticancer effectiveness by topical administration [58, 59]. On the contrary, after incubation with UDL-5FU, it was found that the 5FU reached deep layers of the SC and arrived to the VED (Fig. 7).

Penetration profiles of FUDL-5FU and FCL-5FU were significantly different for both fluorescent labels (Fig. 8A). The cumulative of fluorescence of FITC and Rh-DPPE in the 20 strips (corresponding to the total SC) was around 7.2 folds and 3.9 folds higher, respectively, for FUDL-5FU than for FCL$5 \mathrm{FU}$ (Fig. 8B). Because in this procedure each removed cell layer had nearly the same thickness, the number of tape strips is linearly correlated with the remaining thickness of the SC [12]. According to this, FUDL-5FU penetrated deeper into the SC than FCL-5FU that remained on the skin surface.

The optical scanning along the $z$-axis of the skin pieces (Fig. 9) showed that FITC and Rh-DPPE labels were distributed through the SC layers, particularly in the intercellular space. This result was in concordance with the penetration profile though the SC of FUDL-5FU determined by tape stripping (Fig. 8).

The transversal skin cryosections showed a maximal fluorescence intensity of Rh-DPPE from FUDL-5FU at a depth of $24 \mu \mathrm{m}$ (Fig. 10). Upon hydration, the abdominal SC has a thickness about $40 \mu \mathrm{m}$ [6]; therefore, the lipids were accumulated in the SC. The hydrophilic FITC however was found entering the viable epidermis with a maximal fluorescence intensity at a depth of $120 \mu \mathrm{m}$ (Fig. 10). The same specimens were also subjected to hematoxylin-eosin staining in order to confirm the absence of histological alterations (data not shown). Therefore, the labeled lipids (Rh-DPPE) were distributed through the SC and the fluorescent probe that locates in the liposome aqueous core (FITC) was found both in SC and VED. It is possible that FITC had been released from liposome during the penetration, allowing its diffusion to deeper layers of the skin. In a similar way to the FITC fate after penetration, the $5 \mathrm{FU}$ accumulated in the VED after topical application, only when it was loaded into UDL (Fig. 7). 


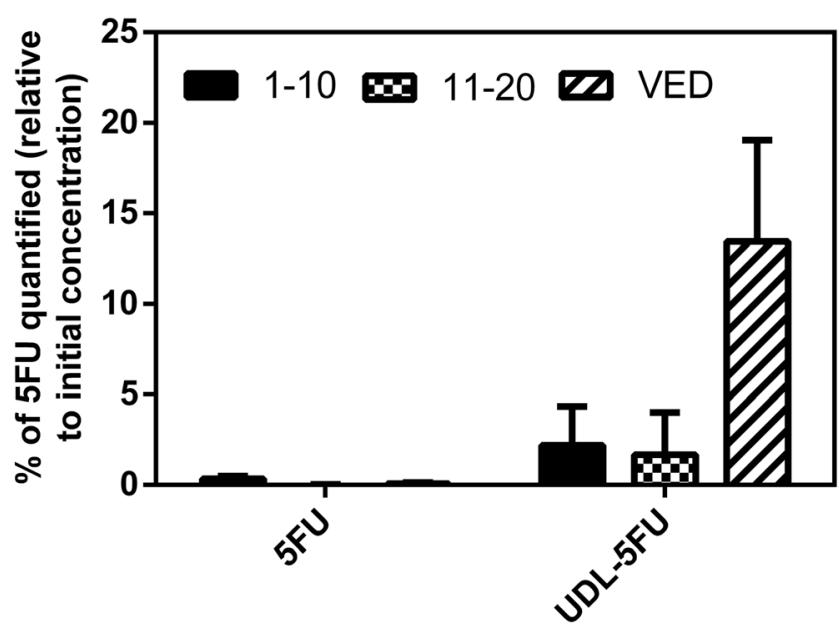

Fig. 7 Penetration profile through the skin by tape stripping. The presence of $5 \mathrm{FU}$ was determined in the upper SC (tapes 1-10), lower SC (tapes 11-20), and viable epidermis and dermis (VED). Results are shown as the percentage of $5 \mathrm{FU}$ quantified in relation to the incubation concentration. Mean $\pm \mathrm{SD}(n=5)$

In sum, ultradeformability seems to be a key factor in the successful delivery of 5FU through the SC. Lamellarity and size are also factors that will determine whether a liposomal formulation can trespass the skin barrier through the intercorneocytic way: when the same lipid mixture used for the ultradeformable matrix in this work was used to prepare multilamellar, bigger liposomes, in another work [60], the formulation did not penetrate the skin. In the past decade, an article proposed a multilamellar, non-ultradeformable liposomal formulation of nearly $5 \mu \mathrm{m}$ in mean size for delivery of 5FU [61]; such a formulation could be good to act as a drug depot on the outer side of the SC, but it would fail to transport $5 \mathrm{FU}$ to deep epidermis.

This achieved delivery of 5FU to deep skin layers by topical application of UDL-5FU could allow the use of this drug for the treatment of non-superficial precancerous and cancerous lesions, since the effectiveness of free $5 \mathrm{FU}$ is limited by its lack of access to the viable epidermis.

\section{In vitro evaluation of antitumor activity}

Cytotoxic effects, uptake, and induction of apoptosis of UDL, UDL-5FU, UDL-5FU-BE, and 5FU were evaluated on the cell lines $\mathrm{HaCaT}$ (as a control of a non-tumor cell line) and SK-Mel-28 (melanoma-derived). BE exhibits antioxidant activity, due to the presence of a polyphenol fraction reach in anthocyanins, in a non-cytotoxic concentration for $\mathrm{HaCaT}$ cells [19]. For this reason, BE was incorporated to the UDL$5 \mathrm{FU}$ formulation with the aim of obtaining a synergistic effect in terms of reducing oxidative stress on non-target cells and collaborating in 5FU-mediated apoptosis processes [37].

The cell viability was measured by the MTT, CV, and NR assays after 4 and $24 \mathrm{~h}$ of treatment (Fig. 11). While the MTT assay is based on the measurement of the mitochondrial succinate dehydrogenase activity of cells, NR and CV stain primarily the lysosomes and the membrane of viable cells, respectively. Since these dyes measure cell viability by different mechanisms, it was thought to be desirable to combine all these assays to obtain a better understanding of the interaction between the formulations and cells. UDL-5FU and UDL$5 \mathrm{FU}-\mathrm{BE}$ at the maximum concentration tested were more
Fig. 8 Skin penetration profile by tape stripping of Rh-DPPE and FITC after $1 \mathrm{~h}$ of non-occlusive application of FUDL-5FU and FCL-5FU (a). Cumulative fluorescence in the 20 strips, $* * p<0.007$ and $* * * p<0.0005$ (b). Mean $\pm \operatorname{SD}(n=5)$

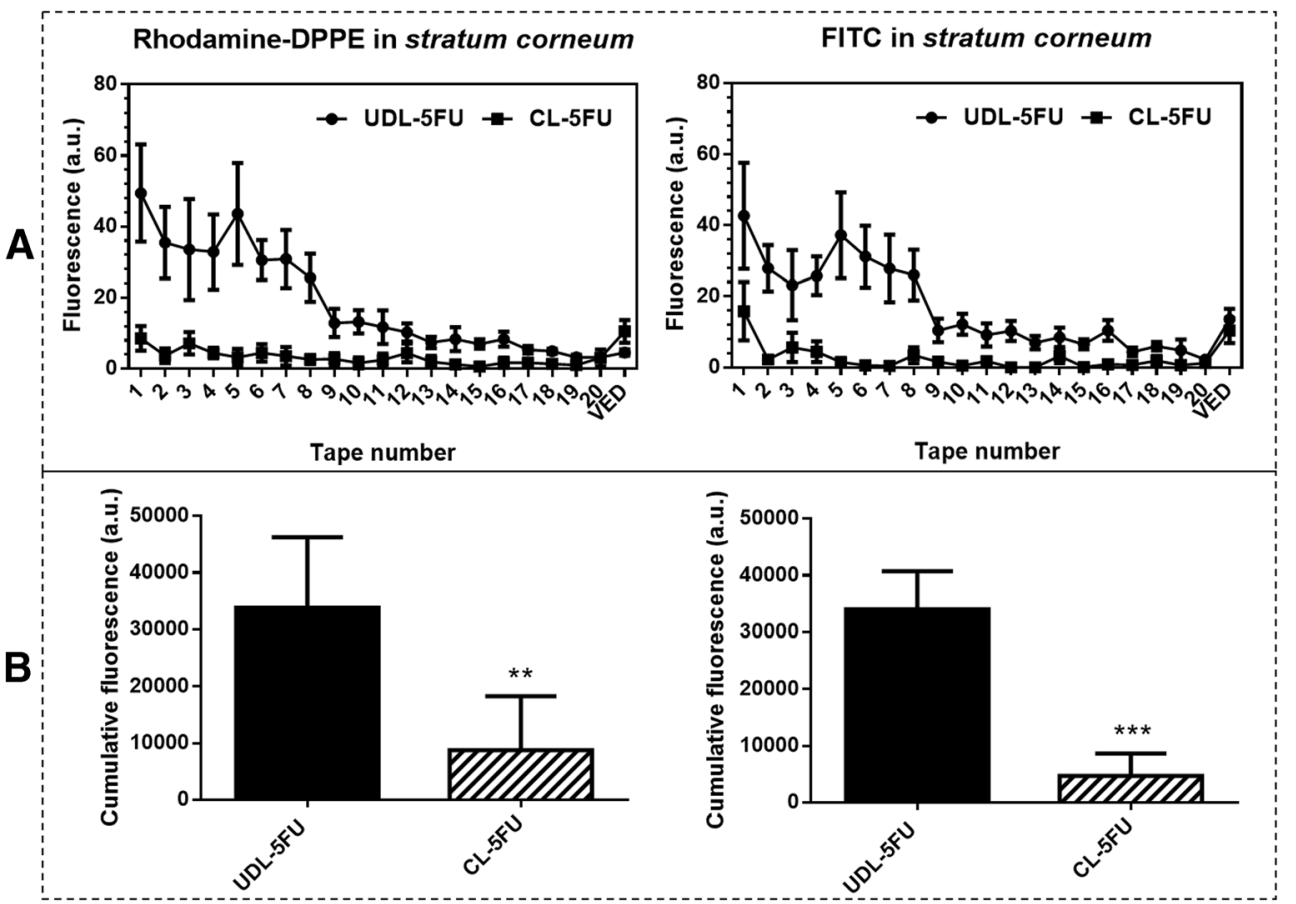


Fig. 9 CLSM images obtained horizontally at $24 \mu \mathrm{m}$ (a), $42 \mu \mathrm{m}$ (b), and $60 \mu \mathrm{m}$ (c) from skin surface upon 1-h incubation with FUDL-5FU. Red and green signals from Rh-DPPE and FITC, respectively

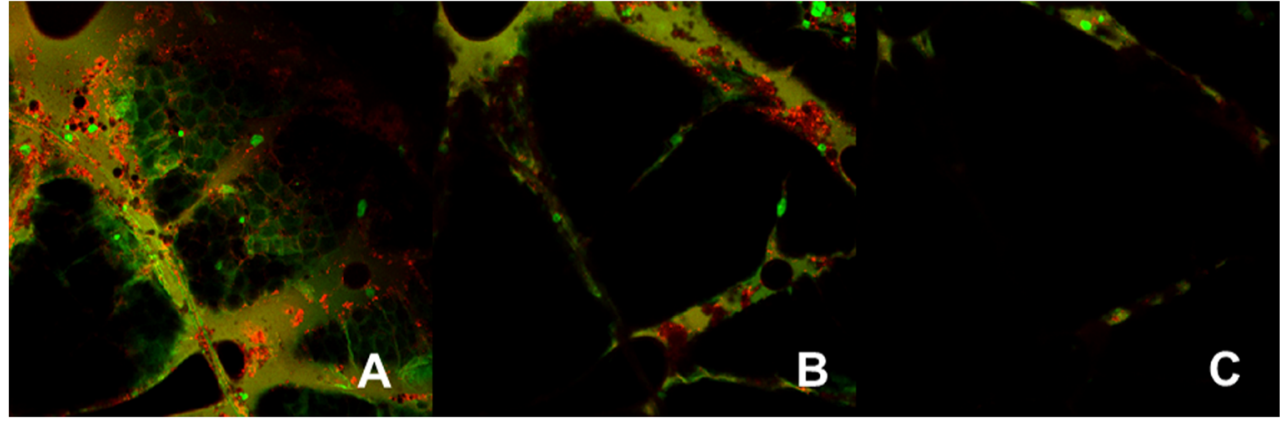

cytotoxic on SK-Mel-28 than on HaCaT at $4 \mathrm{~h}$, while both formulations were more toxic than free 5FU on SK-Mel-28 at $24 \mathrm{~h}$ of treatment (Fig. 11).

On SK-Mel-28, UDL-5FU and UDL-5FU-BE reduced around $70 \%$ with respect to untreated control of the metabolic activity in mitochondria after 4 and $24 \mathrm{~h}$ of treatment. Moreover, both formulations reduced significantly the metabolic activity, about $70 \%$ after $4 \mathrm{~h}$ and $40 \%$ after $24 \mathrm{~h}$ in comparison to free 5FU. The uptake of the NR depends on the capacity of cell to maintain $\mathrm{pH}$ gradients, through the production of ATP [26]. At physiological $\mathrm{pH}$, the dye presents a net charge close to zero, enabling it to penetrate the membranes of the cell. Inside the lysosomes, the dye becomes charged because there is a proton gradient that maintains a $\mathrm{pH}$ lower than that of the cytoplasm and is retained inside by electrostatic interactions with the lysosomal matrix. Therefore, substances that damage the membranes result in a decrease of the uptake and union of NR. The treatment with UDL-5FU and UDL-5FU-BE at 5FU $114.4 \mu \mathrm{M}$ induced a higher membrane damage in comparison to control and free 5FU after 4 and $24 \mathrm{~h}$ of treatment. Nevertheless, this effect did not affect the cell attachment at $4 \mathrm{~h}$, as evidenced by CV. Only UDL-5FU-BE reduced the attachment around $20 \%$ on SKMel-28 and both formulations reduced the attachment around $40 \%$ on $\mathrm{HaCaT}$ at $24 \mathrm{~h}$. The increased toxicity of the encapsulated $5 \mathrm{FU}$ could be related to the liposomal matrix. The
UDL $20.6 \mathrm{mM}$ (SPC) presented higher toxicity rates than formulations and free drugs in all conditions tested (Fig. 11). The reduction of the cytotoxicity after incorporation of 5FU and $\mathrm{BE}$ could be related to the interaction detected in this work between the 5FU and the liposomal membrane.

To study the uptake, both cell lines were incubated with a sublethal concentration of FUDL-5FU during $3 \mathrm{~h}$, a time period long enough to allow uptake and processing of UDL by the two cell lines [62]. To determine if the internalization was achieved by an endocytic pathway, the incubation was realized at 37 and $4{ }^{\circ} \mathrm{C}$ [12]. RAW 264.7 was used as a positive control of phagocytosis (data not shown). SK-Mel-28 showed a higher uptake of FUDL-5FU than $\mathrm{HaCaT}$ at 4 and $37{ }^{\circ} \mathrm{C}$ (Fig. 12). The fluorescence intensity on SK-Mel-28 was lower at $4{ }^{\circ} \mathrm{C}$ and no fluorescence could be observed at $4{ }^{\circ} \mathrm{C}$ on HaCaT. These results could suggest that FUDL-5FU was internalized by both cell lines by endocytic uptake.

The induction of apoptosis and necrosis was followed by flow cytometry after $6 \mathrm{~h}$ of treatment with 5FU, UDL-5FU, and UDL-5FU-BE (Fig. 13). For the detection, the Annexin V-FITC apoptosis kit was used. A differential effect between both cell lines was observed. On SK-Mel-28, both formulations induced a higher rate of apoptosis than free 5FU, while on $\mathrm{HaCaT}$, the induction of a slight percent of non-desirable necrotic cells after incubation with UDL-5FU-BE was observed. Therefore, not only the co-encapsulation with the $\mathrm{BE}$
Fig. 10 CLSM images of cryosectioned skin after $1 \mathrm{~h}$ incubation with FUDL-5FU. Red and green signals from $\mathrm{Rh}$-DPPE and FITC, respectively. The figure on the left is the merge of the images of both fluorophores and the right one is the merge of the first and the transmission image of the skin explant analyzed
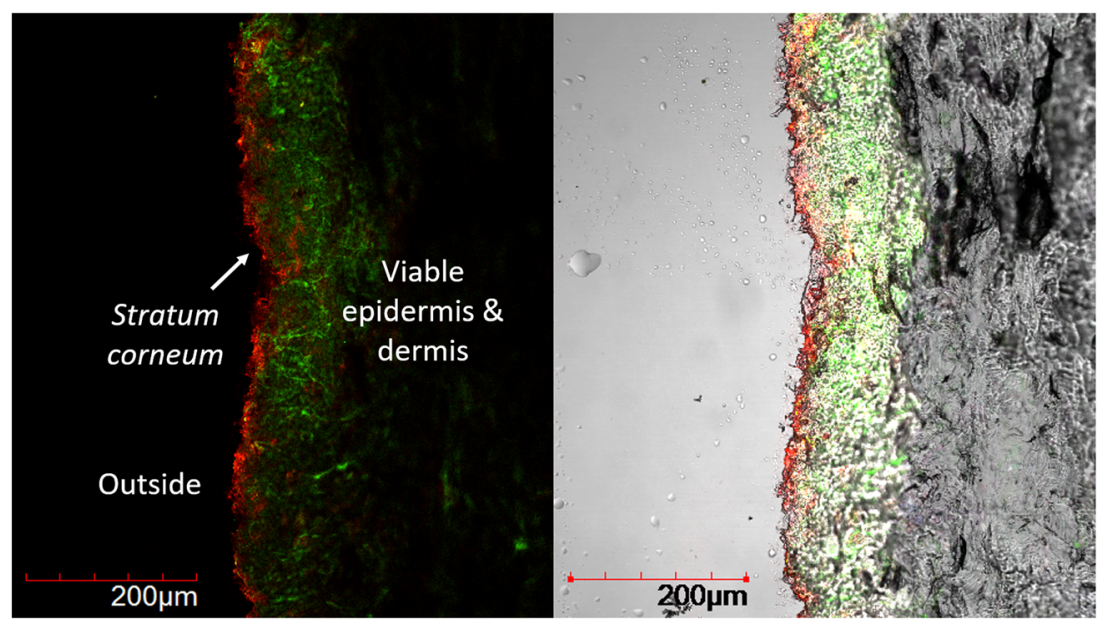


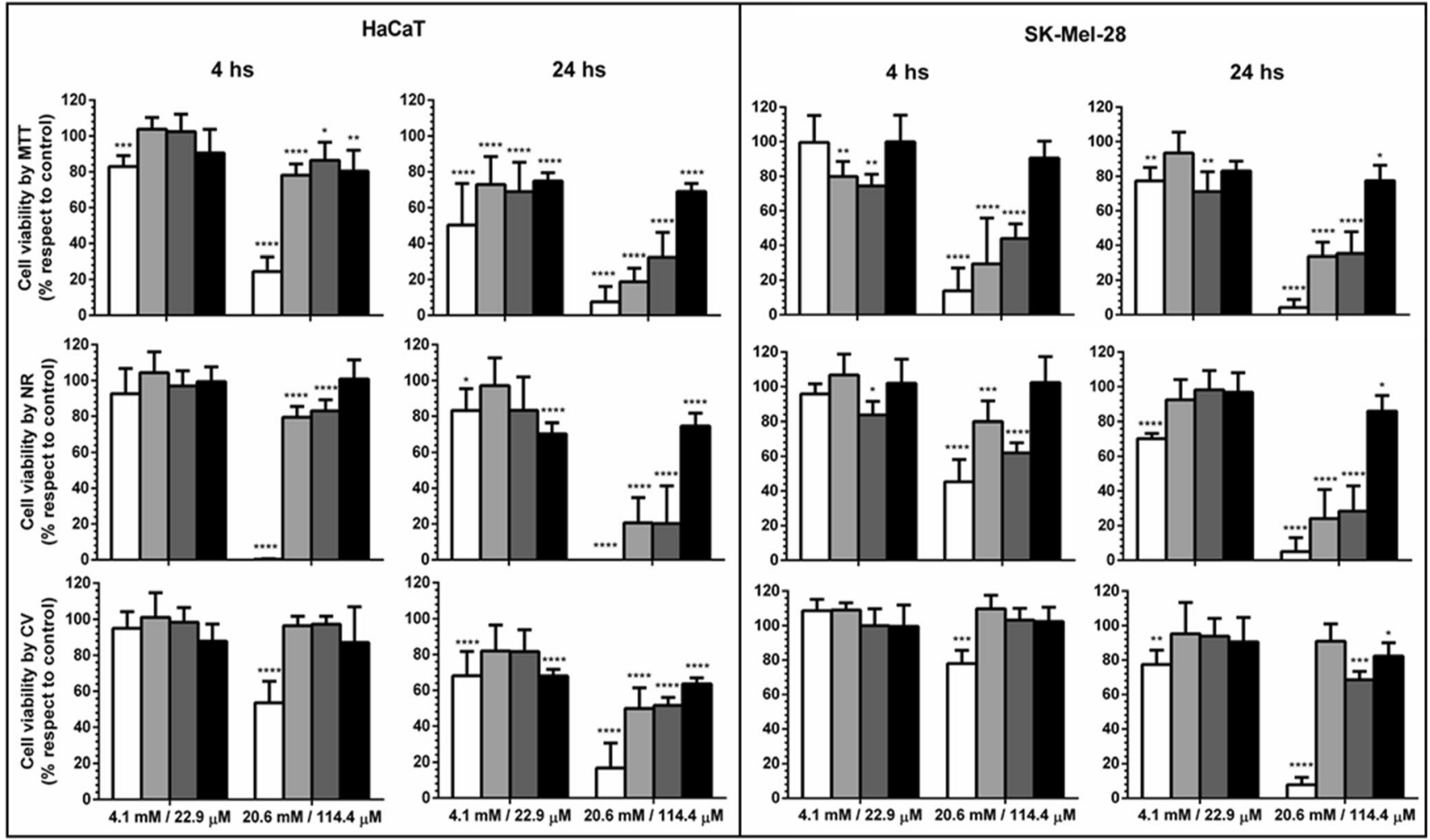

Fig. 11 Cytotoxicity of empty UDL (white), UDL-5FU (light gray), UDL-5FU-BE (dark gray), and free 5FU (black) on HaCaT and SKMel-28 by MTT, NR, and CV at 4 and $24 \mathrm{~h}$. Concentration values are expressed both in $\mathrm{mM}(\mathrm{SPC})$ and $\mu \mathrm{M}(5 \mathrm{FU})$. Data are shown as mean \pm $\mathrm{SD}(n=3), * p<0.05, * * p<0.004, * * * p<0.0006, * * * * p<0.0001$

performance of the drug as in previous works [37]. On the other hand, a short-term treatment with UDL-5FU remarkably produced significant cytotoxic effect only on the melanomaderived line, whereas there were no significant alterations on the non-tumor line.
Fig. 12 Cellular uptake of FUDL-5FU after $3 \mathrm{~h}$ on $\mathrm{HaCaT}$ and SK-Mel-28. Red and green signals correspond to Rh-DPPE and FITC, respectively. Left column shows the FITC label, the middle Rh-DPPE label, and the right the merged labels using ImageJ software

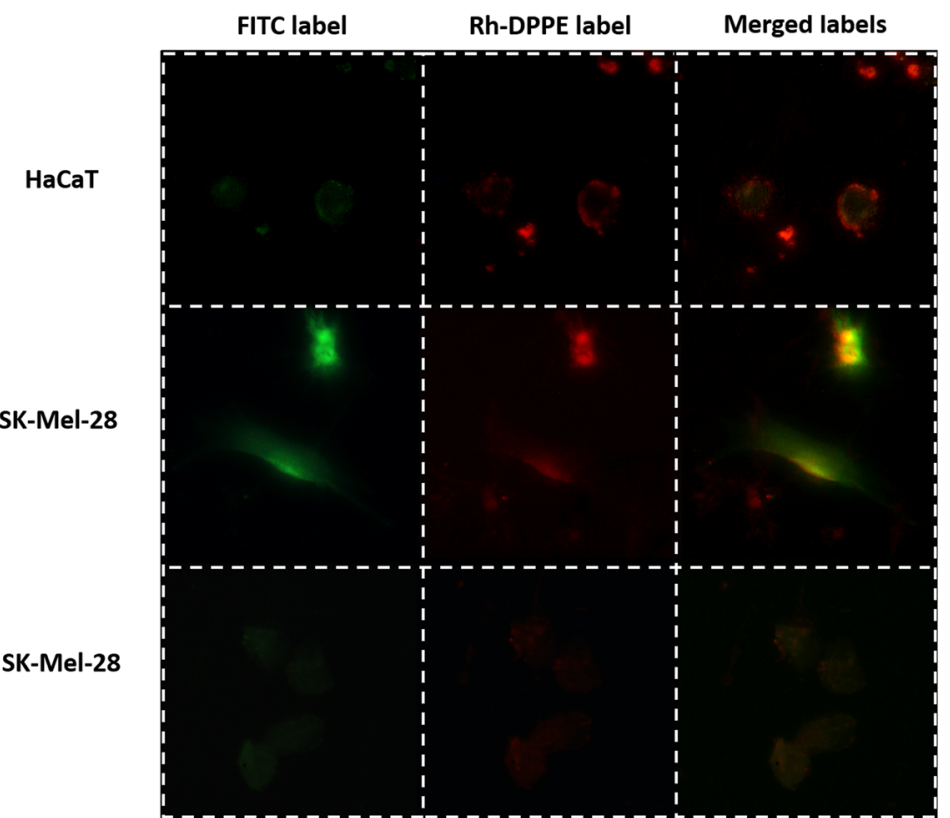

$37^{\circ} \mathrm{C}(40 \mathrm{x})$

$37^{\circ} \mathrm{C}(40 \mathrm{x})$ 


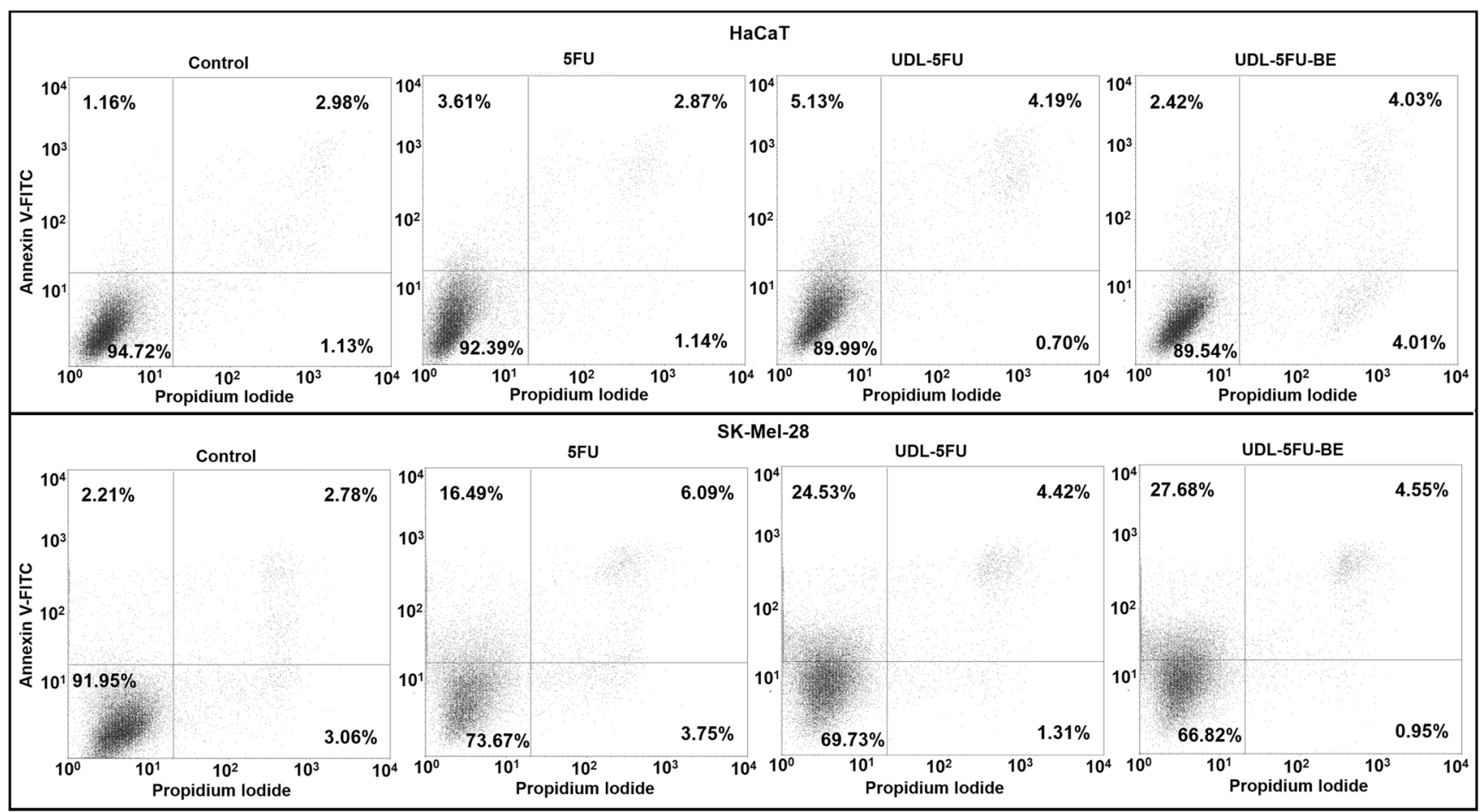

Fig. 13 Flow cytometry analysis for detection and comparison of the apoptotic and necrotic induction by 5FU, UDL-5FU, and UDL-5FU-BE on HaCaT and SK-Mel-28 after $6 \mathrm{~h}$ of incubation. The events were detected by Annexin V-FITC and propidium iodide kit

\section{In vivo toxicity evaluation}

The aim of the studies on zebrafish was to determine the toxicity of the nano-formulation as a preliminary step to further in vivo studies in a mammal model, suitable for toxicity and efficacy assessment after topical application. Zebrafish is a model that offers whole-animal information, impossible to be obtained from in vitro studies. In addition, it is able to predict adverse effects as a previous step to studies in mammals [17]. For these reasons, it is a growing and increasingly accepted model for prediction of non-desirable effects of nano-systems.

Larvae were incubated at $4 \mathrm{dpf}$ with UDL-5FU and 5FU; the treatment was maintained until $7 \mathrm{dpf}$. Swimming activity was assessed with an automated infrared register system at 4 ,
24, 48, and $72 \mathrm{hpi}$. Eight larvae were taken randomly at $72 \mathrm{hpi}$ (7 dpf), were immobilized to be photographed, and filmed to study morphological alterations and cardiac affection.

Free $5 \mathrm{FU}$ decreased the swimming activity, particularly after 48 and $72 \mathrm{hpi}$, for all the concentrations tested (Fig. 14). Larvae treated with 5FU 10 and $20 \mathrm{mM}$ did not present movement at $72 \mathrm{hpi}$. On the other hand, the treatment with UDL-5FU showed an excitation effect in the swimming activity at low concentrations, whereas at the high concentration tested, there was no detectable movement after $24 \mathrm{hpi}$ (Fig. 14). Exposition to 117 and $58.5 \mu \mathrm{M}$ of UDL-5FU (concentration corresponds to $5 \mathrm{FU}$ encapsulated) induced high mortality between 24 and 72 hpi and only at $72 \mathrm{hpi}$, respectively (data not shown).
Fig. 14 Percentage of swimming activity of larvae with respect to the control (untreated larvae) at 4 , 24, 48, and 72 hpi. Data are shown as mean $\pm \mathrm{SD}(n=24)$
$5 \mathrm{FU}$

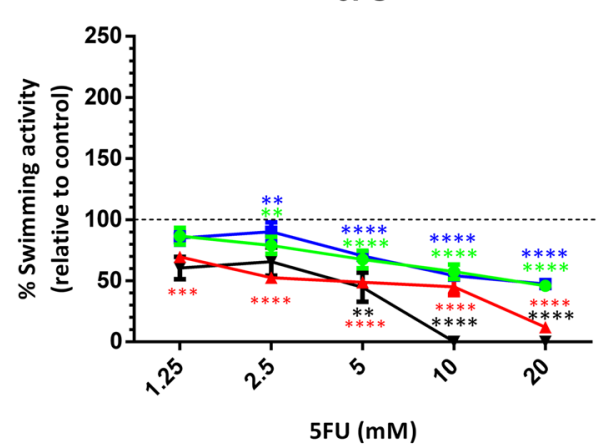

UDL-5FU

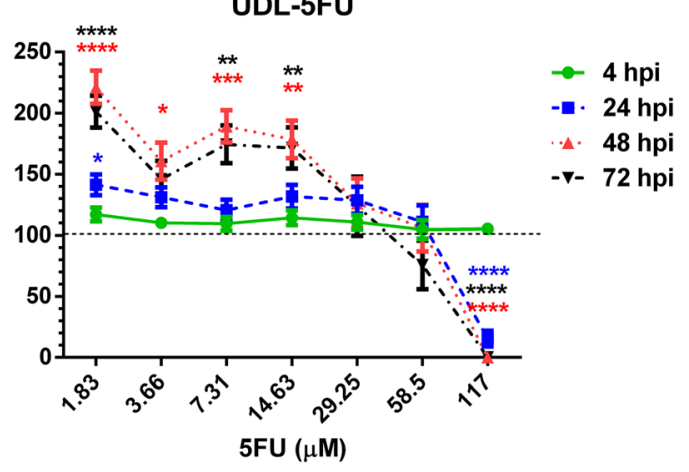



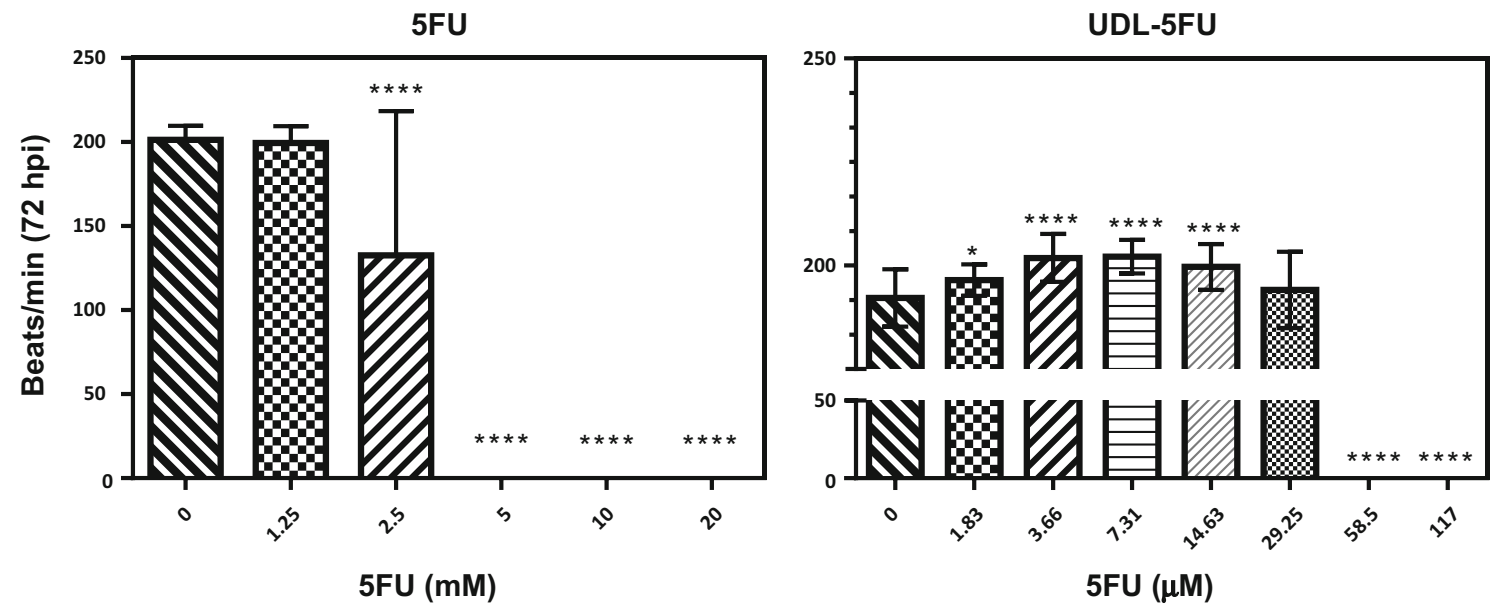

Fig. 15 Beats per minute at 72 hpi. Data are shown as mean $\pm \operatorname{SD}(n=8)$

It is important to consider that because the larvae were randomly took for the study of heart rate and morphological alterations, the absence of heart rate, an evidence of lethality, did not imply that all larvae were death. Free 5FU $2.5 \mathrm{mM}$ produced arrhythmia and larvae had not beats at concentrations higher than $5 \mathrm{mM}$ (Fig. 15). These results are in concordance to data obtained from swimming analysis. The same range of concentrations that induce cardiac effect produced significant swimming activity alterations. All larvae exposed to $5 \mathrm{FU} 10$ and $20 \mathrm{mM}$ were death after $72 \mathrm{hpi}$ (did not present heart beat). UDL-5FU treatment also produced heart rate alteration at 72 hpi. Low concentrations induced an increase of heart rate, whereas high concentrations produced a decrease in heart rate (Fig. 15). The effects observed between swimming activity and heart rate analysis were directly proportional. Concentrations that increased the heart rate are the same that increase the swimming activity, while all larvae exposed to $117 \mu \mathrm{M}$ were dead at $72 \mathrm{hpi}$ (did not present heart beat).
Fig. 16 Larval eye area, rostrocaudal length, and spinal cord length at $72 \mathrm{hpi}$ measured by ImageJ software. Mean $\pm \mathrm{SD}(n=$ 8)

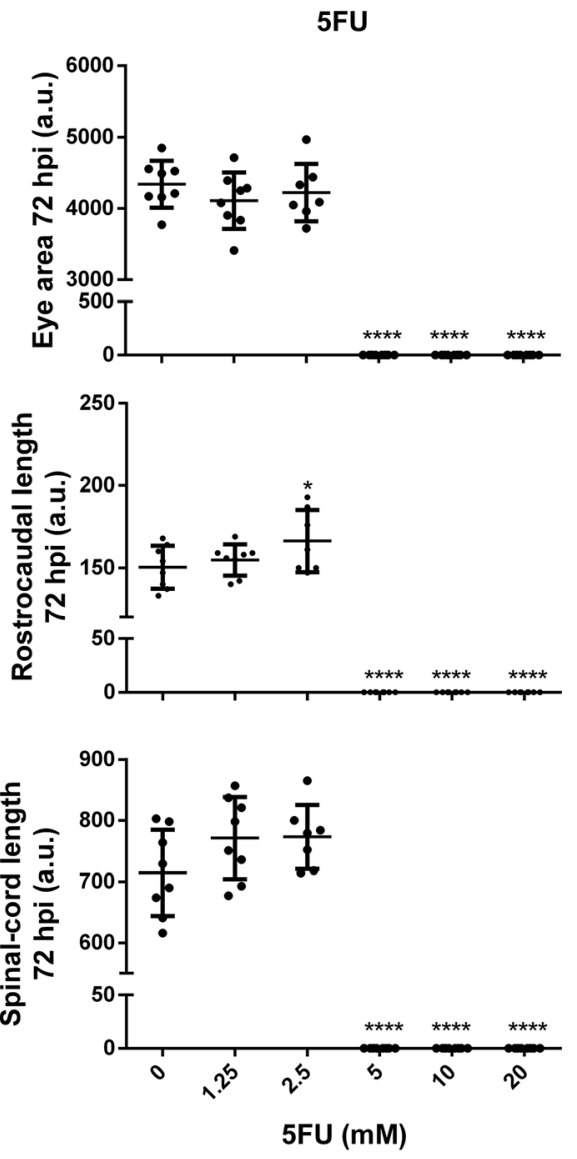

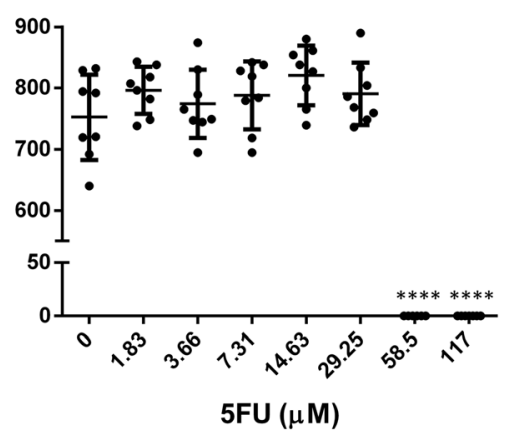




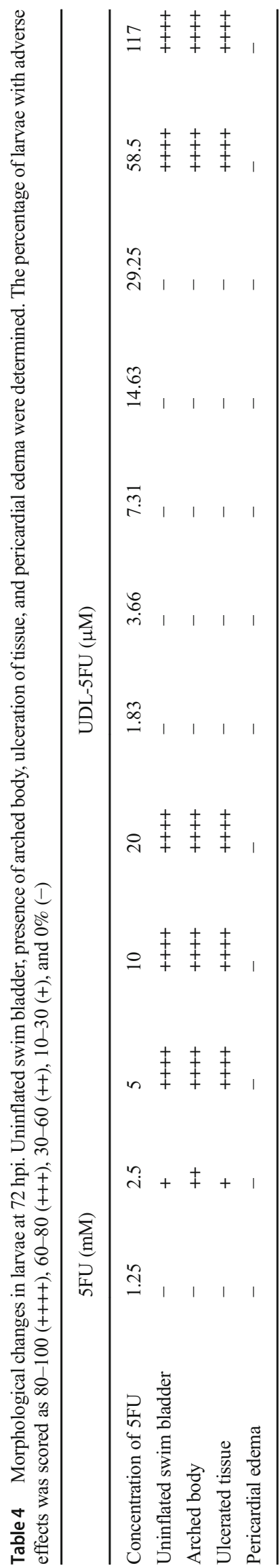

Larvae incubated with concentrations higher than $5 \mathrm{mM}$ of free $5 \mathrm{FU}$ presented severe morphological alterations, whereas those incubated with $2.5 \mathrm{mM}$ presented light-middle effects such as uninflated of swim bladder, presence of arched body, and ulcerated tissue (Fig. 16 and Table 4). Larvae incubated with UDL-5FU presented severe effects at concentrations higher than $58.5 \mu \mathrm{M}$ (Fig. 16 and Table 4). There was no observed pericardial edema at the studied conditions.

Alterations in the swimming activity could be related to morphological changes, alteration in the heart rate, and neurotoxic effects in zebrafish larvae. High or low activity with respect to the control could be indicative of adverse effects on one or more components of the complex neuronal network that governs the early locomotor system (spinal cord and hindbrain) [63]. Because in vertebrates, serotonin plays a key role in the modulation of locomotor movements [64], further studies of changes in the raphe populations of zebrafish brain could give additional evidence of the neurotoxicity of the treatment [33, 65].

UDL-5FU was more toxic than free 5FU, because the formulation induced adverse effects at lower concentration in larvae. This toxicity, in part, could be related to the liposomal matrix and the differential uptake derived by the nature of actives. In a previous study, we observed that empty UDL induced larva toxicity under similar conditions and concentration range [60]. Moreover, it is possible that liposomal 5FU was internalized more than free 5FU because the improved drug delivery by liposomes. Liposomes are composed of biocompatible phospholipids that mimic the properties of biological membranes [66]. Until now, Bucci et al. [60] and this work are the first in studying the developmental toxicity in zebrafish of formulations involving UDL [67].

\section{Conclusion}

The incorporation of 5FU to an UDL formulation could be a way to improve the performance of this drug in topical treatments for deep skin precancerous lesions. UDL-5FU skin penetration was higher than other type of previously tested liposomal formulations. Although the $5 \mathrm{FU}$ interacts with the bilayer, ultradeformability is maintained. UDL-5FU induced apoptosis in vitro in a human melanoma-derived cell line in a higher rate than free 5FU. Besides, this work brings new information about toxicological effects of ultradeformable liposomes in zebrafish, a growing model for prediction of nondesirable effects of nano-systems.

Acknowledgements Jorge Montanari, María Jimena Prieto, C. Facundo Temprana, and Silvia del Valle Alonso are members of CONICET, Argentina. María Natalia Calienni acknowledges fellowships from CONICET Argentina and Ministero degli Affari Esteri e della Cooperazione Internazionale Italia. Authors would like to thank Dr. Humberto Jimenez for the skin explants, The Berry Store for providing 
the blueberry, and Dr. Juan Montes de Oca and Dr. Roberto Candal of INQUIMAE-CONICET.

Funding information This work was supported by a grant from Universidad Nacional de Quilmes and Consejo Nacional de Investigaciones Científicas y Técnicas (CONICET) (PIP 0358, 20142016).

\section{Compliance with ethical standards}

Conflicts of interest The authors declare that they have no conflict of interest.

Ethic statement All animal procedures were performed in strict accordance with International Guidelines for animal care and maintenance. The protocols were approved by the Institutional Committee for the Care and Use of Laboratory Animals and the Ethic Committee of the National University of Quilmes (CE-UNQ 2/2014, CICUAL-UNQ 013-15 and CICUAL-UNQ 014-15) (Buenos Aires, Argentina).

All institutional and national guidelines for the care and use of laboratory animals were followed.

\section{References}

1. Apalla Z, Nashan D, Weller RB, Castellsagué X. Skin cancer: epidemiology, disease burden, pathophysiology, diagnosis, and therapeutic approaches. Dermatol Ther. 2017;7(1):5-19. https://doi. org/10.1007/s13555-016-0165-y.

2. Rigon RB, Oyafuso MH, Fujimura AT, Gonçalez ML, Prado AH, Gremião MPD, et al. Nanotechnology-based drug delivery systems for melanoma antitumoral therapy: a review. Biomed Res Int. 2015;2015:1-22. https://doi.org/10.1155/2015/841817.

3. Naves LB, Dhand C, Venugopal JR, Rajamani L, Ramakrishna S, Almeida L. Nanotechnology for the treatment of melanoma skin cancer. Prog Biomaterials. 2017;6(1-2):1-14. https://doi.org/10. 1007/s40204-017-0063-0.

4. Prausnitz MR, Langer R. Transdermal drug delivery. Nat Biotechnol. 2008;26(11):1261-8. https://doi.org/10.1038/nbt. 1504.

5. Barry BW. Dermatological formulations: percutaneous absorption. vol 18. New York: Marcel Dekker; 1983.

6. El Maghraby GM, Barry BW, Williams AC. Liposomes and skin: from drug delivery to model membranes. Eur J Pharm Sci. 2008;34(4):203-22. https://doi.org/10.1016/j.ejps.2008.05.002.

7. Pirot F, Berardesca E, Kalia YN, Singh M, Maibach HI, Guy RH. Stratum corneum thickness and apparent water diffusivity: facile and noninvasive quantitation in vivo. Pharm Res. 1998;15(3): 492-4. https://doi.org/10.1023/A:1011996903513.

8. Jain S, Patel N, Shah MK, Khatri P, Vora N. Recent advances in lipid-based vesicles and particulate carriers for topical and transdermal application. J Pharm Sci. 2017;106(2):423-45. https://doi.org/ 10.1016/j.xphs.2016.10.001.

9. El Zaafarany GM, Awad GA, Holayel SM, Mortada ND. Role of edge activators and surface charge in developing ultradeformable vesicles with enhanced skin delivery. Int J Pharm. 2010;397(1): 164-72. https://doi.org/10.1016/j.ijpharm.2010.06.034.

10. Cevc G, Blume G. Lipid vesicles penetrate into intact skin owing to the transdermal osmotic gradients and hydration force. Biochimica et Biophysica Acta (BBA) Biomembranes. 1992;1104(1):226-32. https://doi.org/10.1016/0005-2736(92)90154-E.

11. Aghazadeh-Habashi A, Yang Y, Tang K, Lőbenberg R, Doschak MR. Transdermal drug delivery: feasibility for treatment of superficial bone stress fractures. Drug Deliv Transl Res. 2015;5(6):54051. https://doi.org/10.1007/s13346-015-0257-8.
12. Montanari J, Maidana C, Esteva MI, Salomon C, Morilla MJ, Romero EL. Sunlight triggered photodynamic ultradeformable liposomes against Leishmania braziliensis are also leishmanicidal in the dark. J Control Release. 2010;147(3):368-76. https://doi.org/ 10.1016/j.jconrel.2010.08.014.

13. Hernández IP, Montanari J, Valdivieso W, Morilla MJ, Romero EL, Escobar P. In vitro phototoxicity of ultradeformable liposomes containing chloroaluminum phthalocyanine against New World Leishmania species. J Photochem Photobiol B Biol. 2012;117: 157-63. https://doi.org/10.1016/j.jphotobiol.2012.09.018.

14. Paolino D, Cosco D, Muzzalupo R, Trapasso E, Picci N, Fresta M. Innovative bola-surfactant niosomes as topical delivery systems of 5 -fluorouracil for the treatment of skin cancer. Int J Pharm. 2008;353(1):233-42. https://doi.org/10.1016/j.ijpharm.2007.11. 037.

15. Klein E, Stoll HL, Milgrom H, Helm F, Walker MJ. Tumors of the skin. XII. Topical 5-fluorouracil for epidermal neoplasms. J Surg Oncol. 1971;3(3):331-49. https://doi.org/10.1002/jso.2930030314.

16. Cullen SI. Topical fluorouracil therapy for precancers and cancers of the skin. J Am Geriatr Soc. 1979;27(12):529-35.

17. Lee KY, Jang GH, Byun CH, Jeun M, Searson PC, Lee KH. Zebrafish models for functional and toxicological screening of nanoscale drug delivery systems: promoting preclinical applications. Biosci Rep. 2017;37(3):BSR20170199. https://doi.org/10. 1042/BSR20170199.

18. Lin S, Zhao Y, Nel AE. Zebrafish: an in vivo model for nano EHS studies. Small. 2013;9(9-10):1608-18. https://doi.org/10.1002/ smll.201202115.

19. Montanari J, Vera M, Mensi E, Morilla M, Romero E. Nanoberries for topical delivery of antioxidants. J Cosmet Sci. 2012;64(6):46981.

20. Fry DW, White JC, Goldman ID. Rapid separation of low molecular weight solutes from liposomes without dilution. Anal Biochem. 1978;90(2):809-15. https://doi.org/10.1016/0003-2697(78)901720.

21. Stewart JCM. Colorimetric determination of phospholipids with ammonium ferrothiocyanate. Anal Biochem. 1980;104(1):10-4. https://doi.org/10.1016/0003-2697(80)90269-9.

22. Xu D, Zhang J, Cao Y, Wang J, Xiao J. Influence of microcrystalline cellulose on the microrheological property and freeze-thaw stability of soybean protein hydrolysate stabilized curcumin emulsion. LWT- Food Sci Technol. 2016;66:590-7. https://doi.org/10. 1016/j.lwt.2015.11.002.

23. Anibal DE, Arroyo J, Bernik DL. Interfacial properties of liposomes as measured by fluorescence and optical probes. Methods Enzymol. 2003;367:213.

24. Lelkes PI, Miller IR. Perturbations of membrane structure by optical probes: I. Location and structural sensitivity of merocyanine 540 bound to phospholipid membranes. J Membr Biol. 1980;52(1):115. https://doi.org/10.1007/BF01869001

25. Bernik D, Disalvo E. Determination of the dimerization constant of merocyanine 540 at the membrane interface of lipid vesicles in the gel state. Chem Phys Lipids. 1996;82(2):111-23. https://doi.org/10. 1016/0009-3084(96)02568-6.

26. Parasassi T, De Stasio G, Ravagnan G, Rusch R, Gratton E. Quantitation of lipid phases in phospholipid vesicles by the generalized polarization of Laurdan fluorescence. Biophys J. 1991;60(1): 179-89. https://doi.org/10.1016/S0006-3495(91)82041-0.

27. Hollmann A, Delfederico L, De Antoni G, Semorile L, Disalvo EA. Interaction of bacterial surface layer proteins with lipid membranes: synergysm between surface charge density and chain packing. Colloids Surf B: Biointerfaces. 2010;79(1):191-7. https://doi.org/ 10.1016/j.colsurfb.2010.03.046.

28. Marsanasco M, Márquez AL, Wagner JR, Chiaramoni NS, Alonso SV. Bioactive compounds as functional food ingredients: characterization in model system and sensory evaluation in chocolate milk. J 
Food Eng. 2015;166:55-63. https://doi.org/10.1016/j.jfoodeng. 2015.05.007.

29. Montanari J, Perez A, Di Salvo F, Diz V, Barnadas R, Dicelio L, et al. Photodynamic ultradeformable liposomes: design and characterization. Int J Pharm. 2007;330(1):183-94. https://doi.org/10. 1016/j.ijpharm.2006.11.015.

30. Harrison SM, Barry BW, Dugard PH. Effects of freezing on human skin permeability. J Pharm Pharmacol. 1984;36(4):261-2. https:// doi.org/10.1111/j.2042-7158.1984.tb04363.x.

31. Schaefer U, Loth H. An ex-vivo model for the study of drug penetration into human skin. Pharm Res. 1996;13(366):b24.

32. Bichara D, Calcaterra NB, Arranz S, Armas P, Simonetta SH. Setup of an infrared fast behavioral assay using zebrafish (Danio rerio) larvae, and its application in compound biotoxicity screening. J Appl Toxicol. 2014;34(2):214-9. https://doi.org/10.1002/jat.2856.

33. Calienni MN, Feas DA, Igartúa DE, Chiaramoni NS, del Valle Alonso S, Prieto MJ. Nanotoxicological and teratogenic effects: a linkage between dendrimer surface charge and zebrafish developmental stages. Toxicol Appl Pharmacol. 2017;337:1-11. https://doi. org/10.1016/j.taap.2017.10.003.

34. Igartua DE, Calienni MN, Feas DA, Chiaramoni NS, Valle Alonso SD, Prieto MJ. Development of nutraceutical emulsions as Risperidone delivery systems: characterization and toxicological studies. J Pharm Sci. 2015;104(12):4142-52. https://doi.org/10. 1002/jps.24636.

35. Feas DA, Igartúa DE, Calienni MN, Martinez CS, Pifano M, Chiaramoni NS et al. Nutraceutical emulsion containing valproic acid (NE-VPA): a drug delivery system for reversion of seizures in zebrafish larvae epilepsy model. J Pharm Investig. 2017:1-9. https://doi.org/10.1007/s40005-017-0316-x.

36. Celia C, Trapasso E, Cosco D, Paolino D, Fresta M. Turbiscan Lab ${ }^{\circledR}$ Expert analysis of the stability of Ethosomes ${ }^{\circledR}$ and ultradeformable liposomes containing a bilayer fluidizing agent. Colloids Surf B: Biointerfaces. 2009;72(1):155-60. https://doi. org/10.1016/j.colsurfb.2009.03.007.

37. Cosco D, Paolino D, Maiuolo J, Di Marzio L, Carafa M, Ventura $\mathrm{CA}$, et al. Ultradeformable liposomes as multidrug carrier of resveratrol and 5-fluorouracil for their topical delivery. Int J Pharm. 2015;489(1):1-10. https://doi.org/10.1016/j.ijpharm.2015.04.056.

38. López Medrano F, Sánchez Muñoz A, Sánchez Sánchez V, Costa Pérez-Herrero JR. Cardiotoxicidad por 5-fluorouracilo: ¿isquemia o toxicidad miocárdica? Rev Clin Esp. 2001;201(2):106-10. https:// doi.org/10.1016/S0014-2565(01)71381-1.

39. El Maghraby GM, Williams AC, Barry BW. Skin delivery of 5fluorouracil from ultradeformable and standard liposomes in-vitro. J Pharm Pharmacol. 2001;53(8):1069-77. https://doi.org/10.1211/ 0022357011776450 .

40. Glavas-Dodov M, Fredro-Kumbaradzi E, Goracinova K, Simonoska M, Calis S, Trajkovic-Jolevska S, et al. The effects of lyophilization on the stability of liposomes containing 5-FU. Int J Pharm. 2005;291(1):79-86. https://doi.org/10.1016/j.ijpharm. 2004.07.045.

41. Kaiser N, Kimpfler A, Massing U, Burger A, Fiebig H, Brandl M, et al. 5-Fluorouracil in vesicular phospholipid gels for anticancer treatment: entrapment and release properties. Int $\mathrm{J}$ Pharm. 2003;256(1):123-31. https://doi.org/10.1016/S0378-5173(03) 00069-3.

42. Elmeshad A, Mortazavi S, Mozafari M. Formulation and characterization of nanoliposomal 5-fluorouracil for cancer nanotherapy. J Liposome Res. 2014;24(1):1-9. https://doi.org/10.3109/08982104. 2013.810644.

43. Elorza B, Elorza M, Frutos G, Chantres J. Characterization of 5fluorouracil loaded liposomes prepared by reverse-phase evaporation or freezing-thawing extrusion methods: study of drug release. Biochim Biophys Acta Biomembr. 1993;1153(2):135-42. https:// doi.org/10.1016/0005-2736(93)90398-J.
44. El Maghraby GM, Campbell M, Finnin BC. Mechanisms of action of novel skin penetration enhancers: phospholipid versus skin lipid liposomes. Int J Pharm. 2005;305(1):90-104. https://doi.org/10. 1016/j.ijpharm.2005.08.016.

45. Postigo F, Mora M, De Madariaga M, Nonell S, Sagrista M. Incorporation of hydrophobic porphyrins into liposomes: characterization and structural requirements. Int J Pharm. 2004;278(2):239 54. https://doi.org/10.1016/j.ijpharm.2004.03.004.

46. Chiaramoni NS, Speroni L, Taira MC. Alonso SdV. Liposome/ DNA systems: correlation between association, hydrophobicity and cell viability. Biotechnol Lett. 2007;29(11):1637-44. https:// doi.org/10.1007/s10529-007-9454-y.

47. Hirsch-Lerner D, Barenholz Y. Hydration of lipoplexes commonly used in gene delivery: follow-up by laurdan fluorescence changes and quantification by differential scanning calorimetry. Biochim Biophys Acta. 1999;1461(1):47-57. https://doi.org/10.1016/ S0005-2736(99)00145-5.

48. Parasassi T, Gratton E. Membrane lipid domains and dynamics as detected by Laurdan fluorescence. J Fluoresc. 1995;5(1):59-69. https://doi.org/10.1007/BF00718783.

49. Bagatolli LA. To see or not to see: lateral organization of biological membranes and fluorescence microscopy. Biochim Biophys Acta. 2006;1758(10):1541-56. https://doi.org/10.1016/j.bbamem.2006. 05.019 .

50. Lopes S, Simeonova M, Gameiro P, Rangel M, Ivanova G. Interaction of 5-fluorouracil loaded nanoparticles with 1, 2dimyristoyl-sn-glycero-3-phosphocholine liposomes used as a cellular membrane model. J Phys Chem B. 2011;116(1):667-75. https://doi.org/10.1021/jp210088n.

51. El Maghraby G, Williams A, Barry B. Drug interaction and location in liposomes: correlation with polar surface areas. Int J Pharm. 2005;292(1):179-85. https://doi.org/10.1016/j.ijpharm.2004.11. 037.

52. Srivastava R, Shankar M, Tandon A, Nagappa A. Liquid membrane phenomena in anticancer drugs. Studies on 5-fluorouracil and its derivatives. Int J Pharm. 1987;38(1-3):239-45. https://doi.org/10. 1016/0378-5173(87)90120-7.

53. Yoshii N, Okamura E. Kinetics of membrane binding and dissociation of 5-fluorouracil by pulsed-field-gradient ${ }^{19} \mathrm{~F}$ NMR. Chem Phys Lett. 2009;474(4):357-61. https://doi.org/10.1016/j.cplett. 2009.04.078.

54. Okamura E, Yoshii N. Drug binding and mobility relating to the thermal fluctuation in fluid lipid membranes. J Chem Phys. 2008;129(21):12B602.

55. van den Bergh BA, Wertz PW, Junginger HE, Bouwstra JA. Elasticity of vesicles assessed by electron spin resonance, electron microscopy and extrusion measurements. Int $\mathrm{J}$ Pharm. 2001;217(1):13-24. https://doi.org/10.1016/S0378-5173(01) 00576-2.

56. Cosco D, Paolino D, Maiuolo J, Di Marzio L, Carafa M, Ventura $\mathrm{CA}$, et al. Ultradeformable liposomes as multidrug carrier of resveratrol and 5-fluorouracil for their topical delivery. Int J Pharm. 2015;489(1):1-10. https://doi.org/10.1016/j.ijpharm.2015.04.056.

57. Cevc G. Material transport across permeability barriers by means of lipid vesicles. Handb Biol Phys. 1995;1:465-90.

58. Singh BN, Singh RB, Singh J. Effects of ionization and penetration enhancers on the transdermal delivery of 5-fluorouracil through excised human stratum corneum. Int J Pharm. 2005;298(1):98107. https://doi.org/10.1016/j.ijpharm.2005.04.004.

59. Gupta RR, Jain SK, Varshney MAOT. Water-in-oil microemulsions as a penetration enhancer in transdermal drug delivery of 5-fluorouracil. Colloids Surf B: Biointerfaces. 2005;41(1):25-32. https:// doi.org/10.1016/j.colsurfb.2004.09.008.

60. Bucci PL, Prieto MJ, Milla L, Calienni MN, Martínez L, Alonso S, et al. Skin penetration and UV-damage prevention by nanoberries. J Cosmet Dermatol. 2017; https://doi.org/10.1111/jocd.12436. 
61. Glavas-Dodov M, Fredro-Kumbaradzi E, Goracinova K, Calis S, Simonoska M, Hincal AA. 5-Fluorouracil in topical liposome gels for anticancer treatment-formulation and evaluation. Acta Pharm (Zagreb, Croatia). 2003;53(4):241-50.

62. Singh S, Kumar A, Karakoti A, Seal S, Self WT. Unveiling the mechanism of uptake and sub-cellular distribution of cerium oxide nanoparticles. Mol BioSyst. 2010;6(10):1813-20. https://doi.org/ $10.1039 / \mathrm{c} 0 \mathrm{mb} 00014 \mathrm{k}$.

63. Selderslaghs IW, Hooyberghs J, Blust R, Witters HE. Assessment of the developmental neurotoxicity of compounds by measuring locomotor activity in zebrafish embryos and larvae. Neurotoxicol Teratol. 2013;37:44-56. https://doi.org/10.1016/j.ntt.2013.01.003.

64. Airhart MJ, Lee DH, Wilson TD, Miller BE, Miller MN, Skalko $\mathrm{RG}$, et al. Adverse effects of serotonin depletion in developing zebrafish. Neurotoxicol Teratol. 2012;34(1):152-60. https://doi. org/10.1016/j.ntt.2011.08.008.

65. McLean DL, Fetcho JR. Relationship of tyrosine hydroxylase and serotonin immunoreactivity to sensorimotor circuitry in larval zebrafish. J Comp Neurol. 2004;480(1):57-71. https://doi.org/10. 1002/cne.20281.

66. Cole JT, Holland NB. Multifunctional nanoparticles for use in theranostic applications. Drug Deliv Transl Res. 2015;5(3):295309. https://doi.org/10.1007/s13346-015-0218-2.

67. Martinez CS, Igartúa DE, Calienni MN, Feas DA, Siri M, Montanari J et al. Relation between biophysical properties of nanostructures and their toxicity on zebrafish. Biophys Rev. 2017;9(5): 775-91. https://doi.org/10.1007/s12551-017-0294-2. 